\title{
Research on Financial Hedging Decision Based on Exchange Rate Risk in Transnational Supply Chain
}

\author{
Liang Wang $\mathbb{D}$, Xianyan Xiong $\mathbb{D}$, and Mengmeng Hui \\ School of Economics and Management, Xi'an University of Technology, Xi'an, China \\ Correspondence should be addressed to Liang Wang; wangliang@xaut.edu.cn
}

Received 9 February 2021; Revised 31 May 2021; Accepted 25 August 2021; Published 13 September 2021

Academic Editor: Jose Luis Calvo-Rolle

Copyright (c) 2021 Liang Wang et al. This is an open access article distributed under the Creative Commons Attribution License, which permits unrestricted use, distribution, and reproduction in any medium, provided the original work is properly cited.

\begin{abstract}
This paper considers a three-echelon manufacturer-retailer-supplier supply chain, the purpose of which is to investigate the influence of the bilateral exchange rate risks of import and export and the leading company's financial hedging on the decisionmakers of the supply chain. Firstly, it constructs the profit function and the financial hedging decision-making model of each member in the decentralized supply chain. Secondly, it introduces the incentive mechanism of exchange rate risk hedging in the centralized supply chain. Thirdly, from the perspective of wholesale price agreements and revenue-sharing contracts, it discusses the impact of financial hedging behavior and bilateral exchange rate risks on the decision-making process of each member through mathematical modeling. Finally, it explores the relationships of decision variables through simulation analysis. The results illustrate that (i) for decentralized and centralized decision-making, the manufacturer's expected profit and profit variance decrease with the increase of the fluctuations of import and export exchange rates under the hedging strategy for exchange rate risks; (ii) compared with the decentralized supply chain, the manufacturer's expected profit in the centralized supply chain decreases slightly under the revenue-sharing contract; (iii) in the centralized supply chain, if the manufacturer's risk hedging ratio is high, its profit variance is smaller than that of the decentralized supply chain and the expected profits of the retailer and the supplier will increase significantly; and (iv) for the members of the transnational supply chain, centralized decision-making is better than decentralized decision-making.
\end{abstract}

\section{Introduction}

With the continuous development of international trade, the enterprise supply chain is increasingly characterized by globalization. In this context, exchange rate risks in transnational supply chains have already become a hot issue in theoretical and industrial circles [1]. According to a survey by the British "Economist" magazine, exchange rate fluctuation has become the top concern for leaders of 500 multinational companies. Major currencies such as the Japanese yen, Australian dollar, and Swiss francs have experienced annual swings of more than 20 percent against the dollar since 2008, while the British pound and the euro have seen annual swings of more than 30 percent against the greenback. After the "8.11" exchange rate reform in 2015, China's renminbi gradually presents the two-way fluctuation range, which also poses a severe challenge to the management of the transnational supply chains. As of December 2018, Gree Electric Appliances' foreign exchange losses reached 1.6 billion yuan, and the highest foreign exchange gains losses among listed companies have been disclosed. The foreign exchange loss of OFI (Oufei Technology Co., Ltd) was as high as 325 million yuan, $43.82 \%$ of its net profit in the same period, while that of Dongshan Precision was about 74.193 million yuan, $22 \%$ of its net profit in the same period. Therefore, exchange rate risks will affect the performance of each member and the whole supply chain in practice. How to cope with exchange rate risks is an essential problem in transnational supply chain management.

As for the exchange rate risks, financial hedging is an important way to deal with them. The relevant investigation suggested that $60.3 \%$ of companies used financial derivatives, which have significantly decreased the foreign exchange risk 
exposure. At present, some Chinese enterprises, as intermediate nodes in the supply chain, are inevitably affected by the fluctuations of import and export exchange rates. For example, Huawei imported $\$ 6$ billion worth of components from the US every year before 2019 and then manufactured them for sale in Europe, Africa, and other places, according to relevant reports. It means that Huawei, as an intermediate node enterprise in the transnational supply chain, will face the risks of import and export exchange rates. These risks will affect Huawei's marginal profit and its production decisions, which will lead to changes in the operational decisions of the supply chain members through its contractual relationship with upstream and downstream enterprises. This indicates that these bilateral exchange rate risks can be transmitted to the whole supply chain and affect its performance. When the exchange rate changes, it is necessary for multinational enterprises to make timely responses and take effective hedging measures to reduce operational risks of the transnational supply chain and enhance their ability to resist risks. However, many Chinese enterprises have not yet built a sound risk management system against exchange rate risks. Therefore, how exchange rate fluctuations affect transnational enterprises and how to design the management strategies for exchange rate risks are important issues in a transnational supply chain.

The objectives of this paper inquire about the following questions:

(1) When considering the bilateral exchange rate fluctuations of import and export, what are the impacts of exchange rate risks and leading company's hedging strategies on the decision-makers in the transnational supply chain?

(2) Under the effect of the incentive mechanism of exchange rate risk hedging, what are the differences in the impact of exchange rate fluctuations on the profits and decisions of each member in centralized decision-making compared with decentralized decision-making?

Given this, we consider the bilateral exchange rates of import and export, introduce the incentive mechanism of risk hedging, and construct the financial hedging model of decision-makers in the decentralized and centralized transnational supply chain. We investigate the influence of leading company's financial hedging on the decision-makers of the supply chain accordingly.

The innovations of this article are as follows: (i) The profit function and the financial hedging decision-making model of each member in the decentralized supply chain are constructed. (ii) The incentive mechanism of exchange rate risk hedging is introduced in the centralized transnational supply chain. The influence of exchange rate fluctuations and financial hedging strategies on decision-makers of the supply chain under wholesale price agreements and revenue-sharing contracts are investigated. (iii) The comparison research of decentralized and centralized decision-making is carried out through simulation analysis and shows that the former is better than the latter for each member of the transnational supply chain.
The rest of this paper is organized as follows. Section 2 is the literature review. Section 3 constructs the profit functions of decision-makers in decentralized and centralized supply chains and develops the expected profit and optimal decision of each member. Section 4 conducts simulation analysis on the decision variables. Section 5 presents managerial implications. Section 6 provides the conclusions and some topics for future research.

\section{Literature Review}

The literature review mainly involves the following three research fields.

2.1. Identification and Assessment of Exchange Rate Risks and Their Impact on Transnational Supply Chain. For exchange rate risks in transnational supply chains, Manuj and Mentzer [2] believed that exchange rate risks are an unavoidable risk source for decision-makers of transnational supply chains. Liu and Nagurney [3] studied the influence of exchange rate risks on supply chain enterprises participating in offshore outsourcing activities and found that the profits of supply chain members with different risk attitudes vary greatly. Regarding the identification and assessment of exchange rate risks, Ito et al. [4] concluded that the higher the company's dependence on foreign market sales, the greater the foreign exchange exposure. Hernán and Norberto [5] developed the Bayesian method and autoregressive vector model to estimate short-term and long-term paths, concluding that exchange rate risk transmission is nonlinear and related to state and shock dependent. Mahapatra and Bhaduri [6] adopted the two-factor arbitrage pricing model to evaluate the exchange rate risk pricing before and after the financial crisis. They found that multinational enterprises only significantly responded to the exchange rate fluctuations after the financial crisis.

In terms of the influence of exchange rate fluctuations on transnational supply chains, Kim and Park [7] argued that exchange rate risk management contracts could improve the profit of supply chain members to some extent. Li et al. [8] pointed out that the external financial liabilities of multinational enterprises reduced the bilateral exchange rate risks in the transnational supply chain. Huang et al. [9] suggested that exchange rate risks would lead to different total profits of the transnational supply chain through mixed-integer linear programming model solution and numerical experimental model. Thorbecke [10] believed that exchange rate appreciations in Asian supply chains reduce exports and increase imports through the dynamic least squares method.

2.2. Exchange Rate Risk Management Strategy. In the practice of the management strategy for exchange rate risks, Srinivasulu [11] first proposed to divide risk management strategies into operational and financial hedging strategies. Kazaz [12] pointed out that the operational hedging strategy for exchange rate risks is that multinational enterprises choose appropriate market strategies and acquisition strategies to reduce the impact of exchange rate risks on 
them. The financial hedging strategy for exchange rate risks refers to the use of foreign exchange futures and other financial derivatives to reduce the influence of exchange rate risks on the performance of multinational companies. Chowdhry and Howe [13] pointed out that operational hedging strategies are more effective in reducing the influence of long-term exchange rate risks on supply chains, while financial hedging strategies are more effective in lowering the impact of short-term exchange rate risks.

In the study on exchange rate risk management based on operational hedging, Cohen and Huchzermeier [14] utilized the dynamic programming model to evaluate the flexibility value of decision-making enterprises. The research results showed that the flexibility of operational decision-making could maximize the firm value. Kazaz et al. [15] analyzed the influence of allocation and production hedging on the performance of decision-makers in the supply chain. Liu et al. [16] discussed the optimal decision under the risk hedging strategies of the option and the advance purchase discount contracts. Wang and Huang [17] revealed that collaborative decision-making on logistics and financial resources could effectively reduce exchange rate risks and improve the flexibility and performance of the supply chain. Bolandifar and Chen [18] investigated the optimal hedging strategy of risk-neutral firms in supply chain settings, concluding that both processors and retailers benefit from the retailers' pricing power when their margins are linked to purchase cost.

In the study on exchange rate risk management based on financial hedging, Caldentey and Haugh [19] showed that when there is financial hedging in the downstream enterprises, the upstream enterprises can obtain higher profits. Hung et al. [20] assumed that financial hedging strategies for exchange rate risks could effectively improve corporate profits by developing a two-stage model. Kim and Park [7] argued that it is difficult for decision-making enterprises to ensure that financial markets or institutions can provide appropriate financial instruments due to the limitations of financial derivatives in terms of liquidity scale. Bandaly et al. [21] constructed an integrated risk management model to hedge exchange rate risks in the supply chain by employing financial derivatives and operational methods. Liu and Wang [22] concluded that enterprises could improve their operation and hedging decisions when hedging exchange rate risks with futures contracts.

\subsection{Wholesale Price Agreements and Revenue-Sharing Con-} tracts in the Supply Chain. In terms of wholesale price agreements of the supply chain, Han et al. [23] analyzed the pricing and negotiation strategies of e-commerce suppliers and manufacturers under the mixed operation mode. Leng et al. [24] suggested that the supply chain members could benefit from the retailer's quality inspection activities when the retailer had strong negotiation and pricing power. Matsui [25] explored the optimal timing of when one manufacturer should bargain a wholesale price with one retailer in a dual-channel supply chain that consists of the manufacturer and the retailer. Sinha et al. [26] developed a green supply chain inventory model for the integrated production of new items based on deferred payment contracts. Udayakumar et al. [27] framed an inventory model for noninstantaneous deteriorating items considering money inflation and time discounting, where a permissible delay period was offered by the supplier as an alternative to a discount price agreement.

In terms of the revenue-sharing contracts of the supply chain, Zhang et al. [28] found that the suppliers' preference for revenue-sharing and repurchase contracts depends on the ratio of product production cost to the selling price. $\mathrm{Hu}$ and Feng [29] established a revenue-sharing contract supply chain model under supply and demand uncertainty, proving that the buyer's and the supplier's optimal quantities are both nondecreasing of the service requirement. Liu and Yang [30] studied the seller's risk avoidance and promotion decision when the revenue-sharing contracts were adopted in the secondary orders after the sale. Heydari et al. developed [31] a hybrid of greening cost-sharing and revenuesharing contracts (HGRS) to initiate channel coordination and establish a win-win outcome for both parties. Li and Wang [32] took the cost-profit rate as the objective optimization function and built a supply chain optimization and coordination model consisting of one supplier and one retailer under the revenue-sharing contract. Sana [33] studied the optimal green quality and sales prices of the manufacturer and the retailer in both decentralized and centralized systems of a two-echelon supply chain system.

To sum up, although some studies have investigated the influence of exchange rate fluctuations on transnational supply chains, they only consider the relationships between exchange rate fluctuations and the decision-making of each member in the two-echelon supply chain. Meanwhile, there is a lack of comprehensive analysis of financial hedging strategies for exchange rate risks on three-echelon transnational supply chains. Furthermore, although the wholesale price agreements and revenue-sharing contracts have been studied deeply in the supply chain, the previous studies mainly believe that the supply chain members are riskneutral, but these are risk-averse in practice. In particular, the existing literature only adopts one contract strategy and seldom compared the influence of two different contracts on the decision-making of supply chain members. Given this, we take the three-echelon transnational supply chain composed of one manufacturer, one retailer, and one supplier as the research object. Considering the bilateral exchange rates of import and export, we introduce an incentive mechanism in the supply chain. Based on this, we investigate the influence of the leading company's financial hedging for the exchange rate risks on the decision-making process and profit of the supply chain members. Firstly, we construct the expected profit functions and decision-making models of each member in a decentralized supply chain. Secondly, an incentive mechanism of exchange rate risk hedging is introduced in the centralized supply chain. Meanwhile, we compare the impact of financial hedging behaviors and bilateral exchange rate risks on the decisionmaking process of each member from the perspective of wholesale price agreements and revenue-sharing contracts. 
Finally, the relationships of decision variables are explored through simulation analysis, and the results of the decentralized and centralized decision-making are compared simultaneously.

\section{Model}

\subsection{Assumptions and Variables}

3.1.1. Assumptions. According to the basic characteristics of transnational supply chains, this paper puts forward the following assumptions.

Assumption 1. Suppose there is only one manufacturer, one retailer, and one supplier in this three-echelon transnational supply chain, and there is no information asymmetry in the process of decision-making.

Assumption 2. The retailer, the supplier, and the manufacturer come from different countries, respectively. Retailers and suppliers separately sign product sales contracts and raw material purchase contracts with manufacturers in their currency.

Assumption 3. The mode of "zero inventory" is adopted in the transnational supply chain, and there is no inventory cost.

Assumption 4. The cost function of the supplier is $C=m q+\left(n q^{2} / 2\right)$.

Assumption 5. In this three-echelon transnational supply chain, the manufacturer faces import and export exchange rate risks and is a risk-averse enterprise. The manufacturer will buy the corresponding financial derivatives to hedge the exchange rate risks.

\subsubsection{Variables}

$p$ is the selling price of products, and $p=a-b q$. Here, $a$ represents the market size, $b$ denotes the influence coefficient of the product selling price on market demand, and $q$ is the order quantity of the supply chain. In addition, $a$ and $b$ are constants.

$q_{1}$ and $q_{2}$ represent the order quantity of the retailer's products and the sales quantity of the supplier's raw materials, respectively. Furthermore, suppose a unit of product uses a unit of raw materials, so $q=q_{1}=q_{2}$.

$c$ is the cost of products ordered from the manufacturer by the retailer, including transportation, insurance, and handling fees.

$c_{m}$ denotes the manufacturing cost and R\&D expenditure of the manufacturer, excluding the transaction cost for exchange rate risk hedging.

$\omega_{1}$ represents the benchmark wholesale price of products between the manufacturer and the retailer. That is, it denotes the benchmark wholesale price of the retailer's products. $\omega_{2}$ indicates the benchmark selling price of raw materials per unit product between the manufacturer and the supplier. That is, it denotes the benchmark selling price of the supplier's raw materials.

$\widetilde{e}_{1}\left(\widetilde{e}_{2}\right)$ represents the extent to which the manufacturer's sales profit is affected by export (import) exchange rate risks, and $\widetilde{e}_{1} \sim N\left(0, \sigma_{\widetilde{e}_{1}}^{2}\right) \widetilde{e}_{2} \sim N\left(0, \sigma_{\widetilde{e}_{2}}^{2}\right)$.

$\alpha_{1}\left(\alpha_{2}\right)$ indicates the ratio of the manufacturer's export (import) foreign exchange sales profit (purchase expenditure) exposed to export (import) exchange rate risks, and $1-\alpha_{1}\left(1-\alpha_{2}\right)$ represents its hedging ratio of export (import) exchange rate risks.

$\pi$ denotes the total profit function of the transnational supply chain in centralized decision-making.

$\pi_{r}\left(\pi_{s}\right)$ is the profit function of the retailer (the supplier), and $E\left(\pi_{r}\right)\left(E\left(\pi_{s}\right)\right)$ is its expected profit.

$\pi_{m}$ represents the profit function of the manufacturer, $E\left(\pi_{m}\right)$ is its expected profit, and $\operatorname{Var}\left(\pi_{m}\right)$ denotes its profit variance under the financial hedging strategy.

$\pi_{m}^{\prime}$ indicates the profit function of the manufacturer, $E\left(\pi_{m}^{\prime}\right)$ is its expected profit, and $\operatorname{Var}\left(\pi_{m}^{\prime}\right)$ denotes its profit variance in the absence of financial hedging strategy.

$\lambda_{1}\left(\lambda_{2}\right)$ is the transaction cost of financial derivatives required to hedge export (import) exchange rate risks per unit of product (raw material).

$l_{1}\left(l_{2}\right)$ indicates the incentive coefficient for the retailer (the supplier) to incentivize the manufacturer to hedge export (import) exchange rate risks.

$\varphi_{1}$ is the revenue-sharing coefficient between the manufacturer and the retailer, and $\varphi_{1} \in(0,1)$.

$\varphi_{2}$ represents the revenue-sharing coefficient between the manufacturer and the supplier, and $\varphi_{2} \in(0,1)$.

3.2. Research on Financial Hedging Decision in the Decentralized Transnational Supply Chain Based on Exchange Rate Risks. Assume that the transnational supply chain in this paper follows the Stackelberg game, and the manufacturer is the leading company. As the core enterprise of the supply chain, the manufacturer first determines the benchmark wholesale price of products, raw material selling price, and hedging strategy for exchange rate risks. However, as followers, the retailer and the supplier separately provide their optimal order quantity of products and supply quantity of raw materials.

3.2.1. Expected Profit Functions of Decision-Makers. In decentralized decision-making, there is no revenue-sharing between the manufacturer, retailer, and supplier, and all decisions are aimed at maximizing individual interests. The product sales contract between the manufacturer and the retailer and the raw material purchase contract between the manufacturer and the supplier is signed in the domestic currencies of the retailer and the supplier. Therefore, the exchange rate fluctuations between two currencies will 
directly affect the manufacturer's profit but have little influence on the profits of the retailer and the supplier.

According to the assumptions above (Section 3.1.1), the exchange rate fluctuations between currencies in the supply chain have no direct impact on the profits of the retailer and the supplier. Therefore, the profit functions of the retailer and the supplier are as follows:

$$
\begin{aligned}
& \pi_{r}=(a-b q) q-\left(\omega_{1}+c_{r}\right) q, \\
& \pi_{s}=\omega_{2} q-m q-\frac{n q^{2}}{2} .
\end{aligned}
$$

However, for the manufacturer, to reduce the exchange losses caused by exchange rate fluctuations, it will purchase financial derivatives such as foreign exchange futures to hedge the risks of import and export exchange rates. $\lambda_{1}$ and $\lambda_{2}$ are the transaction costs for the manufacturer to hedge the export and import exchange rate risks for a unit of products, respectively. Then, the transaction costs for the manufacturer to purchase foreign exchange derivatives are $\left(1-\alpha_{1}\right) \lambda_{1}$ and $\left(1-\alpha_{2}\right) \lambda_{2}$, respectively. Therefore, the manufacturer's profit function is as follows:

$$
\begin{aligned}
\pi_{m}= & \alpha_{1}\left(\omega_{1}+\widetilde{e}_{1}\right) q+\left(1-\alpha_{1}\right)\left(\omega_{1}+\overline{e_{1}}\right) q-\alpha_{2}\left(\omega_{2}+\widetilde{e}_{2}\right) q \\
& -\left(1-\alpha_{2}\right)\left(\omega_{2}+\overline{e_{2}}\right) q-\left(1-\alpha_{1}\right) q \lambda_{1}-\left(1-\alpha_{2}\right) q \lambda_{2}-c_{m} q .
\end{aligned}
$$

In equation (3), when $\alpha_{1}=1$ and $\alpha_{2}=1$, the manufacturer does not use foreign exchange derivatives to hedge the risks of import and export exchange rates. The manufacturer's foreign exchange sales profit and purchase expenditure are all exposed to the exchange rate risks, that is, $1-\alpha_{1}=0$ and $1-\alpha_{2}=0$. Therefore, when there is no hedging transaction cost, the manufacturer's profit function is as follows:

$$
\pi_{m}^{\prime}=\left(\omega_{1}+\tilde{e}_{1}\right) q-\left(\omega_{2}+\tilde{e}_{2}\right) q-c_{m} q .
$$

According to the Section 3.1.2, $E\left(\widetilde{e}_{1}\right)=0$ and $E\left(\widetilde{e}_{2}\right)=0$. Therefore, if the manufacturer uses the foreign exchange derivatives to hedge the risks of import and export exchange rates, its expected profit and profit variance are as follows:

$$
\begin{aligned}
E\left(\pi_{m}\right)= & \left(\omega_{1}+\bar{e}\right) q-\left(\omega_{2}+\bar{e}\right) q-\left(1-\alpha_{1}\right) q \lambda_{1} \\
& -\left(1-\alpha_{2}\right) q \lambda_{2}-c_{m} q, \\
\operatorname{Var}\left(\pi_{m}\right)= & \alpha_{1}^{2} q^{2} \sigma_{\tilde{e}_{1}}^{2}+\alpha_{2}^{2} q^{2} \sigma_{\tilde{e}_{2}}^{2} .
\end{aligned}
$$

When the manufacturer does not adopt the financial hedging strategy of exchange rate risks, its expected profit and profit variance are as follows:

$$
\begin{aligned}
E\left(\pi_{m}^{\prime}\right) & =\left(\omega_{1}+\bar{e}\right) q-\left(\omega_{2}+\bar{e}\right) q-c_{m} q, \\
\operatorname{Var}\left(\pi_{m}^{\prime}\right) & =q^{2} \sigma_{\tilde{e}_{1}}^{2}+q^{2} \sigma_{\tilde{e}_{2}}^{2},
\end{aligned}
$$

where $E\left(\pi_{m}^{\prime}\right)>E\left(\pi_{m}\right)$, and $\rho>0$. This shows that while the manufacturer gains high profit, it also bears the risks brought by exchange rate fluctuations, thus increasing the uncertainty of profit fluctuations with the exchange rate.
Based on the hypothesis of the manufacturer's risk-aversion, when the exchange rate risks are high, the manufacturer will use foreign exchange derivatives to hedge the risks of import and export exchange rates to reduce the possibility of suffering losses.

Following Cohen and Huchzermeier [14], we can obtain the deterministic profit function of the manufacturer by establishing the mean-variance model, that is,

$$
\mathrm{EU}\left(\pi_{m}\right)=E\left(\pi_{m}\right)-\frac{1}{2} \rho \operatorname{Var}\left(\pi_{m}\right) .
$$

Here, the risk-averse coefficient $\rho>0$. It can be further obtained from equation (8) that

$$
\begin{aligned}
\mathrm{EU}\left(\pi_{m}\right)= & \left(\omega_{1}+\bar{e}\right) q-\left(\omega_{2}+\bar{e}\right) q-\left(1-\alpha_{1}\right) q \lambda_{1}-\left(1-\alpha_{2}\right) q \lambda_{2} \\
& -c_{m} q-\frac{1}{2} \rho\left(\alpha_{1}^{2} q^{2} \sigma_{\tilde{e}_{1}}^{2}+\alpha_{2}^{2} q^{2} \sigma_{e_{2}}^{2}\right) .
\end{aligned}
$$

3.2.2. Decision-Making Models of the Decentralized Supply Chain. Since the transnational supply chain model in this paper consists of one retailer, one supplier, and one manufacturer, there is no competition behavior between multiple retailers and multiple suppliers. In this model, the market demand for the product is determined. Then, to maximize their expected profit, the decision goal of the retailer and the supplier are to obtain the optimal product order quantity and the optimal raw material supply quantity, respectively.

For the benchmark wholesale price of the products $\omega_{1}$ given by the manufacturer, the retailer's optimal decision is as follows:

$$
\max _{q} \pi_{r}=(a-b q) q-\left(\omega_{1}+c_{r}\right) q .
$$

In equation (10), the second-order partial derivative of the retailer's profit function is always less than 0 in decentralized decision-making. This indicates that the retailer's profit is a concave function, and thus there exists an optimal product order quantity to maximize its profit. According to the first-order condition of optimization decision, the optimal order quantity of the products is as follows:

$$
q=\frac{a-\omega_{1}-c_{r}}{2 b} .
$$

For the benchmark selling price of raw materials required per unit of product $\omega_{2}$ given by the manufacturer, the supplier's optimal decision is as follows:

$$
\max _{q} \pi_{s}=\omega_{2} q-m q-\frac{n q^{2}}{2} .
$$

In equation (12), the second-order partial derivative of the supplier's profit function is also always less than 0 . This suggests that the supplier's profit is a concave function, and thus there exists an optimal raw material supply quantity to maximize its profit. Similarly, the supplier's optimal raw material supply quantity is as follows: 


$$
q=\frac{\omega_{2}-m}{n}
$$

In the decentralized supply chain, the product order quantity (or raw material supply quantity) is only unilaterally decided by the retailer (or the supplier). However, since the manufacturer determines the benchmark wholesale price of products and the benchmark selling price of raw materials, its financial hedging strategies may affect the decision-making process and profits of the retailer and the supplier.

In this three-echelon transnational supply chain, the manufacturer is risk-averse and first determines the benchmark wholesale price of the retailer's products, the benchmark selling price of raw materials, and the financial hedging strategy of exchange rate risks. Furthermore, this paper adopts the mean-variance model to obtain the manufacturer's deterministic equivalent profit function, as shown in equation (8). Since we assume that the transnational supply chain adopts the "zero inventory" mode, each member of the transnational supply chain does not have inventory. That is, the order quantity of the retailer is equal to the supply quantity of the supplier, so $q=q_{1}=q_{2}$.

By substituting equations (11) and (13) into equation (9), the manufacturer's deterministic equivalent profit is as follows:

$$
\begin{aligned}
\mathrm{EU}\left(\pi_{m}\right)= & \left(\omega_{1}+\bar{e}\right) q-\left(\omega_{2}+\bar{e}\right) q-\left(1-\alpha_{1}\right) q \lambda_{1}-\left(1-\alpha_{2}\right) q \lambda_{2}-c_{m} q-\frac{1}{2} \rho\left(\alpha_{1}^{2} q^{2} \sigma_{\tilde{e}_{1}}^{2}+\alpha_{2}^{2} q^{2} \sigma_{\tilde{e}_{2}}^{2}\right) \\
= & {\left[\frac{\left(a-c_{r}\right) n-2 b\left(\omega_{2}-m\right)}{n}+\bar{e}\right] \times \frac{\omega_{2}-m}{n}-\left(\omega_{2}+\bar{e}\right) \times \frac{\omega_{2}-m}{n}-\left(1-\alpha_{1}\right) \frac{\omega_{2}-m}{n} \lambda_{1} } \\
& -\left(1-\alpha_{2}\right) \frac{\omega_{2}-m}{n} \lambda_{2}-c_{m} \frac{\omega_{2}-m}{n}-\frac{1}{2} \rho\left(\alpha_{1}^{2}\left(\frac{\omega_{2}-m}{n}\right)^{2} \sigma_{\tilde{e}_{1}}^{2}+\alpha_{2}^{2}\left(\frac{\omega_{2}-m}{n}\right)^{2} \sigma_{\tilde{e}_{2}}^{2}\right) .
\end{aligned}
$$

It can be obtained from $\left(\partial \mathrm{EU}\left(\pi_{m}\right) / \partial \omega_{2}\right)=0,\left(\partial \mathrm{EU}\left(\pi_{m}\right) /\right.$

$\left.\partial \alpha_{1}\right)=0$, and $\left(\partial \mathrm{EU}\left(\pi_{m}\right) / \partial \alpha_{2}\right)=0$ that

$$
\begin{aligned}
& \omega_{2}=\frac{\left(a-c_{r}\right) n-n\left[\lambda_{1}\left(1-\alpha_{1}\right)+\lambda_{2}\left(1-\alpha_{2}\right)\right]-n c_{m}+4 b d+n m+\rho m\left(\alpha_{1}^{2} \sigma_{\tilde{e}_{1}}^{2}+\alpha_{2}^{2} \sigma_{\tilde{e}_{2}}^{2}\right)}{4 b+2 n+\rho\left(\alpha_{1}^{2} \sigma_{\widetilde{e}_{1}}^{2}+\alpha_{2}^{2} \sigma_{\widetilde{e}_{2}}^{2}\right)}, \\
& \alpha_{1}=\frac{\lambda_{1} n}{\rho\left(\omega_{2}-m\right) \sigma_{\tilde{e}_{1}}^{2}}, \\
& \alpha_{2}=\frac{\lambda_{2} n}{\rho\left(\omega_{2}-m\right) \sigma_{\tilde{e}_{2}}^{2}} .
\end{aligned}
$$

By substituting equations (15) and (17) into equation (13), it can be derived that

$$
\begin{aligned}
& \omega_{2}=n \times \frac{a-m-\lambda_{1}-\lambda_{2}-c_{r}-c_{m}}{4 b+2 n}+m, \\
& \alpha_{1}=\frac{\lambda_{1}(4 b+2 n)}{\rho \sigma_{\tilde{e}_{1}}^{2}\left(a-m-\lambda_{1}-\lambda_{2}-c_{r}-c_{m}\right)}, \\
& \alpha_{2}=\frac{\lambda_{2}(4 b+2 n)}{\rho \sigma_{\tilde{e}_{2}}^{2}\left(a-m-\lambda_{1}-\lambda_{2}-c_{r}-c_{m}\right)}, \\
& q=\frac{a-m-\lambda_{1}-\lambda_{2}-c_{r}-c_{m}}{4 b+2 n} .
\end{aligned}
$$

By substituting equation (21) into equation (11), the benchmark wholesale price of products is as follows:

$$
\omega_{1}=a-c_{r}-2 b \times \frac{a-m-\lambda_{1}-\lambda_{2}-c_{r}-c_{m}}{4 b+2 n} .
$$

Proposition 1. In decentralized decision-making, the order quantity of the retailer and the supply quantity of the supplier do not change with the fluctuations of import and export exchange rates. Under the hedging strategy for exchange rate risks, the risk exposure ratio of import and export exchange rates decreases with the increase of the fluctuations of import and export exchange rates, respectively. 
Proof. According to equation (18) to equation (22), the firstorder partial derivative of $\omega_{1}, \omega_{2}, q, \alpha_{1}, \alpha_{2}$ on $\sigma_{\widetilde{e}_{1}}^{2}$ and $\sigma_{\widetilde{e}_{2}}^{2}$ is as follows:

$$
\begin{aligned}
& \frac{\partial \omega_{1}}{\partial \sigma_{\tilde{e}_{1}}^{2}}=0, \\
& \frac{\partial \omega_{1}}{\partial \sigma_{\widetilde{e}_{2}}^{2}}=0, \\
& \frac{\partial \omega_{2}}{\partial \sigma_{\widetilde{e}_{1}}^{2}}=0, \\
& \frac{\partial \omega_{2}}{\partial \sigma_{\tilde{e}_{2}}^{2}}=0, \\
& \frac{\partial q}{\partial \sigma_{\tilde{e}_{1}}^{2}}=0, \\
& \frac{\partial q}{\partial \sigma_{\tilde{e}_{2}}^{2}}=0, \\
& \frac{\partial \alpha_{1}}{\partial \sigma_{\tilde{e}_{1}}^{2}}=0, \\
& \frac{\partial \alpha_{1}}{\partial \sigma_{\tilde{e}_{2}}^{2}}=0, \\
& \frac{\partial \alpha_{2}}{\partial \sigma_{\tilde{e}_{1}}^{2}}=0 \\
& \frac{\partial \alpha_{2}}{\partial \sigma_{\tilde{e}_{2}}^{2}}=0
\end{aligned}
$$

Proposition 1 suggests that the order quantity of the supply chain is not affected by the risks of import and export exchange rates. It is probably because the manufacturer mainly bears the import and export exchange rate risk. Thus, in decentralized decision-making, the retailer does not consider the loss of the manufacturer when determining the order quantity. When the risks of import and export exchange rates are high, the manufacturer will increase the risk hedging ratio, thus reducing its exposure ratio of foreign exchange sales profit and purchase expenditure to exchange rate risks. That means that the manufacturer can increase the positions in foreign exchange derivatives to hedge higher risks. For a risk-averse manufacturer, this behavior is consistent with reality. From a profit-maximizing perspective, since the hedging cost of the unit product's import and export exchange rate risk remains unchanged, the manufacturer has a stronger incentive to increase its risk hedging ratio under the situation of higher exchange rate risks.

By substituting equations (18), (21), and (22) into equations (1) and (2), respectively, the expected profits of the retailer and the supplier are as follows:

$$
\begin{aligned}
& E\left(\pi_{r}\right)=b \times\left(\frac{a-m-\lambda_{1}-\lambda_{2}-c_{r}-c_{m}}{4 b+2 n}\right)^{2}, \\
& E\left(\pi_{s}\right)=\frac{n}{2} \times\left(\frac{a-m-\lambda_{1}-\lambda_{2}-c_{r}-c_{m}}{4 b+2 n}\right)^{2} .
\end{aligned}
$$

The manufacturer's expected profit and profit variance are as follows:

$$
\begin{aligned}
E\left(\pi_{m}\right)= & \left(a-c_{r}-m-\lambda_{1}-\lambda_{2}-c_{m}\right) \times \frac{a-m-\lambda_{1}-\lambda_{2}-c_{r}-c_{m}}{4 b+2 n} \\
& -(2 b+n) \times\left(\frac{a-m-\lambda_{1}-\lambda_{2}-c_{r}-c_{m}}{4 b+2 n}\right)^{2}+\frac{\lambda_{1}^{2}}{\rho \sigma_{\tilde{e}_{1}}^{2}}+\frac{\lambda_{2}^{2}}{\rho \sigma_{\tilde{e}_{2}}^{2}},
\end{aligned}
$$

$$
\operatorname{Var}\left(\pi_{m}\right)=\alpha_{1}^{2} q^{2} \sigma_{\tilde{e}_{1}}^{2}+\alpha_{2}^{2} q^{2} \sigma_{\tilde{e}_{2}}^{2}=\frac{\lambda_{1}^{2}}{\rho^{2} \sigma_{\widetilde{e}_{1}}^{2}}+\frac{\lambda_{2}^{2}}{\rho^{2} \sigma_{\tilde{e}_{2}}^{2}}
$$

Proposition 2. In decentralized decision-making, the expected profits of the retailer and the supplier in the transnational supply chain do not change with the fluctuations of import and export exchange rates. Under the hedging strategy for exchange rate risks, the manufacturer's expected profit and profit variance decrease with the increase of the fluctuations of import and export exchange rates.

Proof. According to equation (24) to equation (27), the firstorder partial derivative of $E\left(\pi_{r}\right), E\left(\pi_{s}\right), E\left(\pi_{m}\right), \operatorname{Var}\left(\pi_{m}\right)$ on $\sigma_{\widetilde{e}_{1}}^{2}, \sigma_{\widetilde{e}_{2}}^{2}$ is as follows:

$$
\begin{gathered}
\frac{\partial E\left(\pi_{r}\right)}{\partial \sigma_{\tilde{e}_{1}}^{2}}=0, \\
\frac{\partial E\left(\pi_{r}\right)}{\partial \sigma_{\tilde{e}_{2}}^{2}}=0, \\
\frac{\partial E\left(\pi_{s}\right)}{\partial \sigma_{\tilde{e}_{1}}^{2}}=0, \\
\frac{\partial E\left(\pi_{s}\right)}{\partial \sigma_{\tilde{e}_{2}}^{2}}=0, \\
\frac{\partial E\left(\pi_{m}\right)}{\partial \sigma_{\tilde{e}_{1}}^{2}}<0, \\
\frac{\partial E\left(\pi_{m}\right)}{\partial \sigma_{\tilde{e}_{2}}^{2}}<0, \\
\frac{\partial \operatorname{Var}\left(\pi_{m}\right)}{\partial \sigma_{\tilde{e}_{1}}^{2}}<0, \\
\frac{\partial \operatorname{Var}\left(\pi_{m}\right)}{\partial \sigma_{\tilde{e}_{2}}^{2}}<0 .
\end{gathered}
$$


According to Proposition 1, in decentralized decisionmaking, the wholesale price of products, benchmark selling price of raw materials, the order quantity of the retailer, and supply quantity of the supplier do not change with the fluctuations of import and export exchange rates. Therefore, the expected profits of the retailer and the supplier are not affected by the risks of import and export exchange rates, as described in Proposition 2. For the manufacturer, its risk exposure ratio decreases as the fluctuations of import and export exchange rates increase. When the manufacturer is exposed to higher exchange rate risks, its foreign exchange sales and purchase expenditure profit remain unchanged. Although the hedging strategy for exchange rate risks can reduce the exchange losses, the transaction cost of risk hedging and the uncertainty of trading may lead to a reduction in expected profit.

\subsection{Research on Financial Hedging Decision in Centralized} Transnational Supply Chain Based on Exchange Rate Risks. In centralized decision-making, a cooperative relationship is established among members to maximize the total profit of the supply chain through wholesale price agreements or revenue-sharing contracts [31]. Therefore, the retailer, the supplier, and the manufacturer are a community of interests. Under the wholesale price agreements, the profits of the overall supply chain can be maximized through the optimal wholesale price of products and the optimal selling price of raw materials. Under the revenue-sharing contract, the manufacturer shares the profit with the retailer, and the supplier shares the profit with the manufacturer. Existing studies, considering the impact of exchange rate risks on the performance of transnational supply chains, find that transnational enterprises are often unwilling to bear exchange rate risks because it will lead to fluctuations in their profits. Therefore, to further reduce the impact of import and export exchange rate fluctuations on the manufacturer's profit, we introduce the hedging mechanism for exchange rate risks. Furthermore, it is assumed that the retailer and the supplier incentivize the manufacturer to buy foreign exchange futures to hedge exchange rate risks through the wholesale price of products and selling prices of raw material, respectively. Therefore, when there is an incentive mechanism of export exchange rate risk hedging, the final wholesale price of the retailer's products is as follows:

$$
\omega_{r}=\omega_{1}+l_{1}\left(1-\alpha_{1}\right)
$$

In equation (29), $l_{1}$ refers to the incentive coefficient for the retailer to incentivize the manufacturer to hedge export exchange rate risks. $\omega_{1}$ is the benchmark wholesale price of the retailer's products when there is no incentive mechanism of hedging export exchange rate risks. Equation (29) shows that under the effect of the incentive mechanism of exchange rate risk hedging, the final wholesale price obtained by the retailer is related to the benchmark wholesale price given by the manufacturer, the incentive degree of export exchange rate risks, and the risk hedging ratio. The greater the exposure ratio of the manufacturer's foreign exchange sales profit to the export exchange rate risks, the smaller the final wholesale price of the products obtained by the retailer. Meanwhile, the greater the incentive coefficient of the retailer to the manufacturer, the higher the final wholesale price of the products.

When there is an incentive mechanism of import exchange rate risk hedging, the final selling price of the supplier's per unit of raw materials is as follows:

$$
\omega_{s}=\omega_{2}-l_{2}\left(1-\alpha_{2}\right) .
$$

In equation (30), $l_{2}$ represents the incentive coefficient for the supplier to incentivize the manufacturer to hedge export exchange rate risks. $\omega_{2}$ is the benchmark selling price of the supplier's raw materials when there is no hedging incentive mechanism for import exchange rate risks. Equation (30) shows that when the supplier incentivizes the manufacturer to hedge import exchange rate risks through the wholesale price of raw material, the higher the hedging ratio of import exchange rate risks by the manufacturer, the lower the final selling price of raw materials obtained by the supplier. Meanwhile, the greater the incentive coefficient of the supplier to the manufacturer, the lower the final selling price of raw material obtained.

\subsubsection{Expected Profit Functions of Decision-Makers}

(1) Expected Profit Functions of Decision-Makers under the Wholesale Price Agreements. Under the wholesale price agreements, the profits of each member and the whole group can be maximized through the optimal wholesale price of products and the selling price of raw materials.

The retailer's profit function is as follows:

$$
\pi_{r}^{*}=(a-b q) q-\left(\omega_{1}+l_{1}\left(1-\alpha_{1}\right)+c_{r}\right) q .
$$

The supplier's profit function is as follows:

$$
\pi_{s}^{*}=\left(\omega_{2}-l_{2}\left(1-\alpha_{2}\right)\right) q-m q-\frac{n q^{2}}{2} .
$$

By substituting equations (29) and (30) into equation (5), the manufacturer's expected profit and profit variance are as follows:

$$
\begin{aligned}
E\left(\pi_{m}^{*}\right)= & \left(\left(\omega_{1}+l_{1}\left(1-\alpha_{1}\right)\right)+\bar{e}\right) q-\left(\omega_{2}-l_{2}\left(1-\alpha_{2}\right)+\bar{e}\right) q \\
& -\left(1-\alpha_{1}\right) q \lambda_{1}-\left(1-\alpha_{2}\right) q \lambda_{2}-c_{m} q,
\end{aligned}
$$

$\operatorname{Var}\left(\pi_{m}^{*}\right)=\alpha_{1}^{2} q^{2} \sigma_{\tilde{e}_{1}}^{2}+\alpha_{2}^{2} q^{2} \sigma_{\tilde{e}_{2}}^{2}$

In equation (33), in centralized decision-making, the manufacturer will increase the positions in financial derivatives to reduce the risk exposure ratio when all members of the supply chain adopt the wholesale price agreements. Therefore, the impact of exchange rate fluctuations on the manufacturer will decrease, the expected profit will eventually increase, and profit variance will decrease. Furthermore, the greater the risk hedging incentives of the retailer and the supplier to the manufacturer, the higher the manufacturer's expected profit. 
By substituting equations (33) and (34) into equation (8), the manufacturer's deterministic profit function under the wholesale price agreements is as follows:

$$
\mathrm{EU}\left(\pi_{m}^{*}\right)=\left(\left(\omega_{1}+\left(l_{1}-\lambda_{1}\right)\left(1-\alpha_{1}\right)\right)+\bar{e}\right) q-\left(\omega_{2}-\left(l_{2}+\lambda_{2}\right)\left(1-\alpha_{2}\right)+\bar{e}\right) q-c_{m} q-\frac{1}{2} \rho\left(\alpha_{1}^{2} q^{2} \sigma_{\widetilde{e}_{1}}^{2}+\alpha_{2}^{2} q^{2} \sigma_{\widetilde{e}_{2}}^{2}\right) .
$$

(2) Expected Profit Functions of Decision-Makers under the Revenue-Sharing Contract. The manufacturer shares profit with the retailer through the revenue-sharing contract. The retailer receives $\varphi_{1}$ proportion of products' wholesale profit, and the remaining $1-\varphi_{1}$ is transferred to the manufacturer. The supplier shares profit with the manufacturer through the revenue-sharing contract. The manufacturer receives $\varphi_{2}$ proportion of raw materials' selling profit, while the supplier receives $1-\varphi_{2}$. Therefore, the retailer's profit function is as follows:

$$
\pi_{r}^{* *}=\varphi_{1}(a-b q) q-\left(\omega_{1}+l_{1}\left(1-\alpha_{1}\right)+c_{r}\right) q .
$$

The supplier's profit function is as follows:

$$
\begin{aligned}
\pi_{s}^{* *}= & \left(1-\varphi_{2}\right)\left[\alpha_{1}\left(\left(\omega_{1}+l_{1}\left(1-\alpha_{1}\right)\right)+\tilde{e}_{1}\right) q+\left(1-\alpha_{1}\right)\left(\left(\omega_{1}+l_{1}\left(1-\alpha_{1}\right)\right)+\overline{e_{1}}\right) q\right] \\
& +\left(\omega_{2}-l_{2}\left(1-\alpha_{2}\right)\right) q-m q-\frac{n q^{2}}{2} .
\end{aligned}
$$

The manufacturer's profit function is as follows:

$$
\begin{aligned}
\pi_{m}^{* *}= & \left(1-\varphi_{1}\right)(a-b q) q+\varphi_{2} \alpha_{1}\left(\left(\omega_{1}+l_{1}\left(1-\alpha_{1}\right)\right)+\widetilde{e}_{1}\right) q+\varphi_{2}\left(1-\alpha_{1}\right)\left(\left(\omega_{1}+l_{1}\left(1-\alpha_{1}\right)\right)+\overline{e_{1}}\right) q \\
& -\alpha_{2}\left(\left(\omega_{2}-l_{2}\left(1-\alpha_{2}\right)\right)+\widetilde{e}_{2}\right) q-\left(1-\alpha_{2}\right)\left(\left(\omega_{2}-l_{2}\left(1-\alpha_{2}\right)\right)+\overline{e_{2}}\right) q-\left(1-\alpha_{1}\right) q \lambda_{1}-\left(1-\alpha_{2}\right) q \lambda_{2}-c_{m} q .
\end{aligned}
$$

Thus, under the revenue-sharing contract, the manufacturer's expected profit and profit variance are as follows:

$$
\begin{aligned}
E\left(\pi_{m}^{* *}\right) & =\left(1-\varphi_{1}\right)(a-b q) q+\varphi_{2}\left(\left(\omega_{1}+l_{1}\left(1-\alpha_{1}\right)\right)+\overline{e_{1}}\right) q-\left(\left(\omega_{2}-l_{2}\left(1-\alpha_{2}\right)\right)+\overline{e_{2}}\right) q-\left(1-\alpha_{1}\right) q \lambda_{1}-\left(1-\alpha_{2}\right) q \lambda_{2}-c_{m} q, \\
\operatorname{Var}\left(\pi_{m}^{* *}\right) & =\varphi_{2}^{2} \alpha_{1}^{2} q^{2} \sigma_{e_{1}}^{2}+\alpha_{2}^{2} q^{2} \sigma_{e_{2}}^{2} .
\end{aligned}
$$

By substituting equations (39) and (40) into equation (8), the manufacturer's deterministic profit function is as follows:

$$
\begin{aligned}
\mathrm{EU}\left(\pi_{m}^{* *}\right)= & \left(1-\varphi_{1}\right)(a-b q) q+\varphi_{2}\left(\left(\omega_{1}+l_{1}\left(1-\alpha_{1}\right)\right)+\overline{e_{1}}\right) q-\left(\left(\omega_{2}-l_{2}\left(1-\alpha_{2}\right)\right)+\overline{e_{2}}\right) q \\
& -\left(1-\alpha_{1}\right) q \lambda_{1}-\left(1-\alpha_{2}\right) q \lambda_{2}-c_{m} q-\frac{1}{2} \rho\left(\varphi_{2}^{2} \alpha_{1}^{2} q^{2} \sigma_{\tilde{e}_{1}}^{2}+\alpha_{2}^{2} q^{2} \sigma_{\tilde{e}_{2}}^{2}\right) .
\end{aligned}
$$




\subsubsection{Decision-Making Models of the Centralized Supply Chain}

(1) Decision-Making Models of the Centralized Supply Chain under Wholesale Price Agreements. Under the wholesale price agreements, the total profit function of the centralized transnational supply chain is as follows:

$$
\begin{aligned}
\pi & =\mathrm{EU}\left(\pi_{m}^{*}\right)+\pi_{r}^{*}+\pi_{s}^{*} \\
& =(a-b q) q-c_{r} q-m q-\frac{n q^{2}}{2}-\left(1-\alpha_{1}\right) q \lambda_{1}-\left(1-\alpha_{2}\right) q \lambda_{2}-c_{m} q-\frac{1}{2} \rho\left(\alpha_{1}^{2} q^{2} \sigma_{\widetilde{e}_{1}}^{2}+\alpha_{2}^{2} q^{2} \sigma_{\tilde{e}_{2}}^{2}\right) .
\end{aligned}
$$

According to the optimal decision conditions $(\partial \pi / \partial q)=0,\left(\partial \pi / \partial \alpha_{1}\right)=0$, and $\left(\partial \pi / \partial \alpha_{2}\right)=0$, the simultaneous equations can be solved as follows:

$$
\begin{aligned}
& q^{*}=\frac{a-m-\lambda_{1}-\lambda_{2}-c_{r}-c_{m}}{2 b+n}, \\
& \alpha_{1}^{*}=\frac{\lambda_{1}(2 b+n)}{\rho \sigma_{\tilde{e}_{1}}^{2}\left(a-m-\lambda_{1}-\lambda_{2}-c_{r}-c_{m}\right)},
\end{aligned}
$$

$$
\alpha_{2}^{*}=\frac{\lambda_{2}(2 b+n)}{\rho \sigma_{\tilde{e}_{2}}^{2}\left(a-m-\lambda_{1}-\lambda_{2}-c_{r}-c_{m}\right)} \text {. }
$$

Proposition 3. In centralized decision-making, wholesale price agreements can increase the order quantity of the supply chain while increasing the ratio of the manufacturer's risk hedging.

Proof. From equation (43), it can be obtained that

$$
q^{*}=\frac{a-m-\lambda_{1}-\lambda_{2}-c_{r}-c_{m}}{2 b+n}=2 \times \frac{a-m-\lambda_{1}-\lambda_{2}-c_{r}-c_{m}}{4 b+2 n}=2 q>q .
$$

From equations (44) and (45), it can be derived that

$$
\begin{aligned}
& \alpha_{1}^{*}=\frac{\lambda_{1}(2 b+n)}{\rho \sigma_{e_{1}}^{2}\left(a-m-\lambda_{1}-\lambda_{2}-c_{r}-c_{m}\right)}=\frac{1}{2} \times \frac{\lambda_{1}(4 b+2 n)}{\rho \sigma_{e_{1}}^{2}\left(a-m-\lambda_{1}-\lambda_{2}-c_{r}-c_{m}\right)}=\frac{1}{2} \alpha_{1}, \\
& \alpha_{2}^{*}=\frac{\lambda_{2}(2 b+n)}{\rho \sigma_{\tilde{e}_{2}}^{2}\left(a-m-\lambda_{1}-\lambda_{2}-c_{r}-c_{m}\right)}=\frac{1}{2} \times \frac{\lambda_{2}(4 b+2 n)}{\rho \sigma_{\tilde{e}_{2}}^{2}\left(a-m-\lambda_{1}-\lambda_{2}-c_{r}-c_{m}\right)}=\frac{1}{2} \alpha_{2} .
\end{aligned}
$$

Therefore, the following relation can be derived:

$$
\begin{aligned}
& \left(1-\alpha_{1}^{*}\right)>\left(1-\alpha_{1}\right), \quad \begin{array}{l}
\text { and }(32), \text { respectively, the expected profits of the } \\
\text { the supplier are as follows: }
\end{array} \\
\left(1-\alpha_{2}^{*}\right)>\left(1-\alpha_{2}\right) . & \\
E\left(\pi_{r}^{*}\right)= & \left(a-\left(\omega_{1}+l_{1}\left(1-\frac{\lambda_{1}(2 b+n)}{\rho \sigma_{\tilde{e}_{1}}^{2}\left(a-m-\lambda_{1}-\lambda_{2}-c_{r}-c_{m}\right)}\right)\right)-c_{r}\right) \times \frac{a-m-\lambda_{1}-\lambda_{2}-c_{r}-c_{m}}{2 b+n} \\
& -b \times\left(\frac{a-m-\lambda_{1}-\lambda_{2}-c_{r}-c_{m}}{2 b+n}\right)^{2}, \\
E\left(\pi_{s}^{*}\right)= & \left(\omega \omega_{2}-l_{2}\left(1-\frac{\lambda_{2}(2 b+n)}{\rho \sigma_{\tilde{e}_{2}}^{2}\left(a-m-\lambda_{1}-\lambda_{2}-c_{r}-c_{m}\right)}\right)-d\right) \times \frac{a-m-\lambda_{1}-\lambda_{2}-c_{r}-c_{m}}{2 b+n} \\
& -\frac{m}{2} \times\left(\frac{a-m-\lambda_{1}-\lambda_{2}-c_{r}-c_{m}}{2 b+n}\right)^{2} .
\end{aligned}
$$

By substituting equations (43)-(45) into equations (31) and (32), respectively, the expected profits of the retailer and 
In centralized decision-making, the order quantity of the retailer's products is not affected by the exchange rate risks of the manufacturer. Under the incentive mechanism of exchange rate risk hedging, the wholesale price of the retailer's products is affected by export exchange rate risks, so the fluctuations of the export exchange rate will also affect the retailer's expected profit. Similarly, the supplier's expected profit is also affected by the fluctuations of the import exchange rate.

By substituting equations (43)-(49) into equations (36) and (37), respectively, the expected profit and profit variance of the manufacturer are as follows:

$$
\begin{aligned}
E\left(\pi_{m}^{*}\right)= & \left.\left(\omega_{1}-\omega_{2}-\left(1-\frac{\lambda_{1}(2 b+n)}{\rho \sigma_{\tilde{e}_{1}}^{2}\left(a-m-\lambda_{1}-\lambda_{2}-c_{r}-c_{m}\right)}\right)\left(l_{1}-\lambda_{1}\right) \times \frac{a-m-\lambda_{1}-\lambda_{2}-c_{r}-c_{m}}{2 b+n}\right)\left(l_{2}-\lambda_{2}\right)-c_{m}\right) \\
& -\left(1-\frac{\lambda_{2}(2 b+n)}{\rho \sigma_{\tilde{e}_{2}}^{2}\left(a-m-\lambda_{1}-\lambda_{2}-c_{r}-c_{m}\right)}\right. \\
& \times \frac{a-m-\lambda_{1}-\lambda_{2}-c_{r}-c_{m}}{2 b+n}, \\
\operatorname{Var}\left(\pi_{m}^{*}\right)= & \frac{\lambda_{1}^{2}}{\rho^{2} \sigma_{\tilde{e}_{1}}^{2}}+\frac{\lambda_{2}^{2}}{\rho^{2} \sigma_{\tilde{e}_{2}}^{2}} .
\end{aligned}
$$

In equations (51) and (52), under the wholesale price agreements, the manufacturer's expected profit and profit variance decrease with the increase in the fluctuations of the import and export exchange rates. In centralized decisionmaking with the objective of maximizing the total profit of the multinational supply chain, to achieve cooperation between the retailer, the supplier, and the manufacturer in a supply chain, it is necessary to ensure that the total profit of the centralized supply chain is greater than the sum of the profits of the three members in the decentralized decisionmaking. In addition, each member of the centralized supply chain can get a higher profit than the decentralized decisionmaking. Therefore, in centralized decision-making, the wholesale price agreements should meet the following conditions:

$$
\left\{\begin{array}{l}
E\left(\pi_{r}^{*}\right)>E\left(\pi_{r}\right), \\
E\left(\pi_{s}^{*}\right)>E\left(\pi_{s}\right), \\
\operatorname{EU}\left(\pi_{m}^{*}\right)>\operatorname{EU}\left(\pi_{m}\right) .
\end{array}\right.
$$

By solving equation (53), the following equation can be

$$
\left\{\begin{array}{l}
\omega_{1}^{*}<a-c_{r}-\frac{5 b}{2} \times \frac{a-m-\lambda_{1}-\lambda_{2}-c_{r}-c_{m}}{4 b+2 n}-l_{1}\left(1-\frac{\lambda_{1}(2 b+n)}{\rho \sigma_{e_{1}}^{2}\left(a-m-\lambda_{1}-\lambda_{2}-c_{r}-c_{m}\right)}\right), \\
\omega_{2}^{*}>d+\frac{a-m-\lambda_{1}-\lambda_{2}-c_{r}-c_{m}}{2 b+n} \times \frac{5 k}{8}+l_{2}\left(1-\frac{\lambda_{2}}{\rho \sigma_{e_{2}}^{2}} \times \frac{(2 b+n)}{\left(a-m-\lambda_{1}-\lambda_{2}-c_{r}-c_{m}\right)}\right), \\
\omega_{1}^{*}-\omega_{2}^{*}>\frac{a-m+3\left(\lambda_{1}+\lambda_{2}+c_{m}\right)-c_{r}}{4}-\left(l_{1}+l_{2}\right)+\left(\frac{\lambda_{1} l_{1}}{\rho \sigma_{\tilde{e}_{1}}^{2}}+\frac{\lambda_{2} l_{2}}{\rho \sigma_{e_{2}}^{2}}\right) \times \frac{2 b+n}{a-m-\lambda_{1}-\lambda_{2}-c_{r}-c_{m}}
\end{array} .\right.
$$

In equation (54), exchange rate fluctuations influence the wholesale price of the retailer's products and the selling price of the supplier's raw material. As the risk hedging ratio of the manufacturer is affected by the fluctuations of import and export exchange rates, the risk hedging incentive degree of both the retailer and the supplier to the manufacturer will be determined by the manufacturer's risk hedging ratio. Therefore, the benchmark wholesale price of the retailer's products and the benchmark selling price of the supplier's raw materials will also be affected by the exchange rate fluctuations, as described in Proposition 4. Furthermore, the fluctuations in import and export exchange rates are transmitted among members of the transnational supply chains through the benchmark wholesale price of products and the benchmark selling price of raw materials. Therefore, the expected profits of the retailer and the supplier will also be affected by the exchange rate risks, as described in Proposition 5. 
Proposition 4. In centralized decision-making, compared with decentralized decision-making, the wholesale price agreements can lower the benchmark wholesale price of the retailer's products and raise the selling price of the supplier's raw materials. Furthermore, the benchmark wholesale price of the retailer's products decreases with the increase of export exchange rate fluctuations, while the benchmark selling price of the supplier's raw materials decreases with the increase of import exchange rate fluctuations.

Proof. From equation (54), it can be obtained that

$$
\begin{aligned}
\omega_{1}^{*}<a & -c_{r}-\frac{5 b}{2} \times \frac{a-m-\lambda_{1}-\lambda_{2}-c_{r}-c_{m}}{4 b+2 n}-l_{1}\left(1-\frac{\lambda_{1}(2 b+n)}{\rho \sigma_{e_{1}}^{2}\left(a-m-\lambda_{1}-\lambda_{2}-c_{r}-c_{m}\right)}\right) \\
& =\omega_{1}-\frac{b\left(a-m-\lambda_{1}-\lambda_{2}-c_{r}-c_{m}\right)}{4 b+2 n}-l_{1}\left(1-\frac{\lambda_{1}(2 b+n)}{\rho \sigma_{\tilde{e}_{1}}^{2}\left(a-m-\lambda_{1}-\lambda_{2}-c_{r}-c_{m}\right)}\right) .
\end{aligned}
$$

Because $\left(\left(a-m-\lambda_{1}-\lambda_{2}-c_{r}-c_{m}\right) /(4 b+2 n)\right)>0$, we have $\omega_{1}^{*}<\omega_{1}$. Similarly, $\omega_{2}^{*}>\omega_{2}$.

Therefore, $\omega_{1}^{*}$ decreases as $\sigma_{\widetilde{e}_{1}}^{2}$ increases, and $\omega_{2}^{*}$ increases as $l_{1}$ increases.

Proposition 5. In centralized decision-making, when the wholesale price agreements are adopted, the expected profits of the retailer and the supplier decrease with the increase of the fluctuations of export exchange rate and import exchange rate, respectively. Moreover, the manufacturer's expected profit decreases as the fluctuations of import and export exchange rates increase.

Proof. From equations (49) to (52), we can get the following:

$$
\begin{gathered}
\frac{\partial E\left(\pi_{r}^{*}\right)}{\partial \sigma_{\tilde{e}_{1}}^{2}}<0, \\
\frac{\partial E\left(\pi_{r}^{*}\right)}{\partial \sigma_{\tilde{e}_{2}}^{2}}=0, \\
\frac{\partial E\left(\pi_{s}^{*}\right)}{\partial \sigma_{\tilde{e}_{1}}^{2}}=0, \\
\frac{\partial E\left(\pi_{s}^{*}\right)}{\partial \sigma_{\tilde{e}_{2}}^{2}}<0, \\
\frac{\partial E\left(\pi_{m}^{*}\right)}{\partial \sigma_{\tilde{e}_{1}}^{2}}<0, \\
\frac{\partial E\left(\pi_{m}^{*}\right)}{\partial \sigma_{e_{2}}^{2}}<0, \\
\frac{\partial \operatorname{Var}\left(\pi_{m}^{*}\right)}{\partial \sigma_{\tilde{e}_{1}}^{2}}<0, \\
\frac{\partial \sigma_{\tilde{e}_{2}}^{2}\left(\pi_{m}^{*}\right)}{2}<0 .
\end{gathered}
$$

(2) Decision-Making Models of the Centralized Supply Chain under Revenue-Sharing Contract. Under the revenue-sharing contract, the total profit function of the centralized transnational supply chain is as follows:

$$
\begin{aligned}
\pi= & \pi_{r}^{* *}+\pi_{s}^{* *}+\operatorname{EU}\left(\pi_{m}^{* *}\right) \\
= & (a-b q) q-c_{r} q-m q-\frac{n q^{2}}{2}-\left(1-\alpha_{1}\right) q \lambda_{1}-\left(1-\alpha_{2}\right) q \lambda_{2} \\
& -c_{m} q-\frac{1}{2} \rho\left(\varphi_{2}^{2} \alpha_{1}^{2} q^{2} \sigma_{\tilde{e}_{1}}^{2}+\alpha_{2}^{2} q^{2} \sigma_{\tilde{e}_{2}}^{2}\right) .
\end{aligned}
$$

The first-order partial derivative of equation (57) on $q$ is as follows:

$$
\begin{aligned}
\frac{\partial \pi}{\partial q}= & a-2 b q-n q-c_{r}-m-\lambda_{1}\left(1-\alpha_{1}\right)-\lambda_{2}\left(1-\alpha_{2}\right)-c_{m} \\
& -\frac{1}{2} \rho\left(\varphi_{2}^{2} \alpha_{1}^{2} \sigma_{\widetilde{e}_{1}}^{2}+\alpha_{2}^{2} \sigma_{\tilde{e}_{2}}^{2}\right) \times 2 q .
\end{aligned}
$$

From $(\partial \pi / \partial q)=0$, the optimal order quantity of the transnational supply chain under the revenue-sharing contracts is as follows:

$$
q^{* *}=\frac{a-c_{r}-m-\lambda_{1}\left(1-\alpha_{1}\right)-\lambda_{2}\left(1-\alpha_{2}\right)-c_{m}}{2 b+n+\rho\left(\varphi_{2}^{2} \alpha_{1}^{2} \sigma_{\widetilde{e}_{1}}^{2}+\alpha_{2}^{2} \sigma_{\widetilde{e}_{2}}^{2}\right)}
$$

For the benchmark wholesale price $\omega_{1}^{*}$ given by the manufacturer, the retailer's optimal decision is as follows:

$$
\max _{q} E\left(\pi_{r}^{* *}\right)=\varphi_{1}(a-b q) q-\left(\omega_{1}+l_{1}\left(1-\alpha_{1}\right)+c_{r}\right) q
$$

For the benchmark selling price $\omega_{2}^{*}$ given by the manufacturer, the supplier's optimal decision is as follows: 


$$
\left.\max _{q} E\left(\pi_{s}^{* *}\right)=\left(\omega_{2}-l_{2}\left(1-\alpha_{2}\right)\right) q-m q-\frac{n q^{2}}{2}+\left(1-\varphi_{2}\right)\left(\omega_{1}+l_{1}\left(1-\alpha_{1}\right)\right)+\overline{e_{1}}\right) q
$$

Under the revenue-sharing contract, the benchmark wholesale price of the retailer's products and the benchmark selling price of the supplier's raw materials given by the manufacturer are as follows:

$$
\left\{\begin{array}{l}
\omega_{1}^{* *}=\varphi_{1}\left(a-2 b \frac{a-c_{r}-m-\lambda_{1}\left(1-\alpha_{1}\right)-\lambda_{2}\left(1-\alpha_{2}\right)-c_{m}}{2 b+n+\rho\left(\varphi_{2}^{2} \alpha_{1}^{2} \sigma_{\tilde{e}_{1}}^{2}+\alpha_{2}^{2} \sigma_{\tilde{e}_{2}}^{2}\right)}\right)-c_{r}-l_{1}\left(1-\alpha_{1}\right) \\
\omega_{2}^{* *}=\frac{a-c_{r}-m-\lambda_{1}\left(1-\alpha_{1}\right)-\lambda_{2}\left(1-\alpha_{2}\right)-c_{m}}{2 b+n+\rho\left(\varphi_{2}^{2} \alpha_{1}^{2} \sigma_{\tilde{e}_{1}}^{2}+\alpha_{2}^{2} \sigma_{\tilde{e}_{2}}^{2}\right)} \times\left(n+\left(1-\varphi_{2}\right) 2 b \varphi_{1}\right)+m \\
-\left(1-\varphi_{2}\right)\left(a \varphi_{1}-c_{r}\right)+l_{2}\left(1-\alpha_{2}\right) .
\end{array}\right.
$$

In equation (62), in centralized decision-making, when each member of the transnational supply chain adopts the revenue-sharing contracts, the retailer will get a lower benchmark wholesale price of products, and the supplier will obtain a higher benchmark selling price of raw materials. Possible reasons are as follows. Under the revenue-sharing contract, if the manufacturer gives the retailer a lower wholesale price, the wholesale profit obtained by the manufacturer will decrease, leading to a decrease in the expected profit. When the retailer incentivizes the manufacturer to hedge export exchange rate risk with higher wholesale prices, this will increase the manufacturer's wholesale revenue and expected profit. Similarly, if the manufacturer is given a higher wholesale price for raw materials, its purchasing expenses will increase and its revenue will decrease. When the supplier incentivizes the manufacturer to hedge import exchange rate risk with lower wholesale prices of raw materials, it will reduce the manufacturer's purchasing expenditures and increase its revenue. Therefore, the larger the manufacturer's financial derivatives position is, that is, the greater the risk hedge ratio is, the smaller the wholesale benchmark price of the products will be for the retailer and the higher the wholesale benchmark price of the raw materials will be for the supplier. From the perspective of maximizing the total profit of the centralized supply chain, the optimal product order quantity (raw material supply quantity) of the transnational supply chain is as follows:

$$
q^{* *}=\frac{a-c_{r}-m-\lambda_{1}\left(1-\alpha_{1}\right)-\lambda_{2}\left(1-\alpha_{2}\right)-c_{m}}{2 b+n+\rho\left(\varphi_{2}^{2} \alpha_{1}^{2} \sigma_{\tilde{e}_{1}}^{2}+\alpha_{2}^{2} \sigma_{\tilde{e}_{2}}^{2}\right)}
$$

By substituting equations (62) and (63) into equations (43) and (43), respectively, the manufacturer's expected profit and profit variance under the revenue-sharing contracts are, respectively, as follows:

$$
\begin{aligned}
E\left(\pi_{m}^{* *}\right)= & \frac{a-c_{r}-m-\lambda_{1}\left(1-\alpha_{1}\right)-\lambda_{2}\left(1-\alpha_{2}\right)-c_{m}}{2 b+n+\rho\left(\varphi_{2}^{2} \alpha_{1}^{2} \sigma_{\tilde{e}_{1}}^{2}+\alpha_{2}^{2} \sigma_{\tilde{e}_{2}}^{2}\right)} \times\left(a-\varphi_{2} c_{r}-m-\left(1-\alpha_{1}\right) \lambda_{1}-\left(1-\alpha_{2}\right) \lambda_{2}-c_{m}\right) \\
& -\left(\frac{a-c_{r}-m-\lambda_{1}\left(1-\alpha_{1}\right)-\lambda_{2}\left(1-\alpha_{2}\right)-c_{m}}{2 b+n+\rho\left(\varphi_{2}^{2} \alpha_{1}^{2} \sigma_{\widetilde{e}_{1}}^{2}+\alpha_{2}^{2} \sigma_{\widetilde{e}_{2}}^{2}\right)}\right)^{2} \times\left[b+2 b \varphi_{1} \varphi_{2}+n+b \varphi_{1}\right] \\
\operatorname{Var}\left(\pi_{m}^{* *}\right)= & \left(\frac{a-c_{r}-m-\lambda_{1}\left(1-\alpha_{1}\right)-\lambda_{2}\left(1-\alpha_{2}\right)-c_{m}}{2 b+n+\rho\left(\varphi_{2}^{2} \alpha_{1}^{2} \sigma_{\widetilde{e}_{1}}^{2}+\alpha_{2}^{2} \sigma_{\tilde{e}_{2}}^{2}\right)}\right)^{2} \times\left(\varphi_{2}^{2} \alpha_{1}^{2} \sigma_{\widetilde{e}_{1}}^{2}+\alpha_{2}^{2} \sigma_{\tilde{e}_{2}}^{2}\right) .
\end{aligned}
$$


In equations (64) and (65), for the centralized decisionmaking, under the hedging strategy of exchange rate risks, as the positions in financial derivative increases, the manufacturer's profit variance decreases continuously. In addition, the manufacturer's expected profit is uncertain as the exchange rate fluctuates. In this case, the manufacturer should seek the optimal risk hedging ratio to ensure that it can obtain a considerable expected profit and a small profit variance.

By substituting equations (62) and (63) into equation (39), the retailer's expected profit under the revenue-sharing contracts is as follows:

$$
E\left(\pi_{r}^{* *}\right)=b \varphi_{1}\left(\frac{a-c_{r}-m-\lambda_{1}\left(1-\alpha_{1}\right)-\lambda_{2}\left(1-\alpha_{2}\right)-c_{m}}{2 b+n+\rho\left(\varphi_{2}^{2} \alpha_{1}^{2} \sigma_{\widetilde{e}_{1}}^{2}+\alpha_{2}^{2} \sigma_{\widetilde{e}_{2}}^{2}\right)}\right)^{2} .
$$

Equation (66) shows that under the revenue-sharing contract, the retailer's expected profit is affected by the fluctuations of import and export exchange rates. The larger the manufacturer's financial derivative position is, that is, the greater the risk hedge ratio is, the lower the resulting exchange loss is likely to be. Therefore, the manufacturer will give the retailer a lower wholesale price of the products. On the contrary, if the risk hedging ratio is smaller, the risk exposure ratio will be higher, which may lead to a large exchange loss. In this case, the benchmark wholesale price of the retailer's products may be higher. The greater the wholesale price, the higher the ordering cost and the lower the expected profit. Therefore, under the revenue-sharing contract, the retailer's expected profit decreases as the exchange rate fluctuations increase.

By substituting equations (62) and (63) into equation (40), the supplier's expected profit under the revenuesharing contracts is as follows:

$$
\begin{aligned}
E\left(\pi_{s}^{* *}\right)= & {\left[\left(\frac{n}{2}+2 b \varphi_{1}-\left(1-\varphi_{2}\right) 2 b\right) \frac{a-c_{r}-m-\lambda_{1}\left(1-\alpha_{1}\right)-\lambda_{2}\left(1-\alpha_{2}\right)-c_{m}}{2 b+n+\rho\left(\varphi_{2}^{2} \alpha_{1}^{2} \sigma_{\tilde{e}_{1}}^{2}+\alpha_{2}^{2} \sigma_{\widetilde{e}_{2}}^{2}\right)}-\left(1-\varphi_{2}\right) c_{r}\right] } \\
& \times \frac{a-c_{r}-m-\lambda_{1}\left(1-\alpha_{1}\right)-\lambda_{2}\left(1-\alpha_{2}\right)-c_{m}}{2 b+n+\rho\left(\varphi_{2}^{2} \alpha_{1}^{2} \sigma_{\widetilde{e}_{1}}^{2}+\alpha_{2}^{2} \sigma_{\tilde{e}_{2}}^{2}\right)} .
\end{aligned}
$$

In equation (67), the supplier's expected profit decreases with the increase of the fluctuations of import and export exchange rates. The greater the exchange rate fluctuations, the smaller the raw material wholesale price given by the manufacturer to the supplier, the less the raw material sales quantity, and the lower the expected profit. Therefore, under the revenue-sharing contract, the supplier's expected profit decreases as the exchange rate fluctuations increase.

Proposition 6. Under the revenue-sharing contract, the expected profits of the retailer and the supplier decrease as the fluctuations of import and export exchange rates increase.

Proof. From equations (66) and (67), it can be obtained that

$$
\begin{aligned}
& \frac{\partial E\left(\pi_{r}^{* *}\right)}{\partial \phi_{1}}>0, \\
& \frac{\partial E\left(\pi_{r}^{* *}\right)}{\partial \sigma_{\tilde{e}_{1}}^{2}}<0,
\end{aligned}
$$$$
\frac{\partial E\left(\pi_{r}^{* *}\right)}{\partial \sigma_{\tilde{e}_{2}}^{2}}<0,
$$$$
\frac{\partial E\left(\pi_{s}^{* *}\right)}{\partial \phi_{1}}>0,
$$

$$
\frac{\partial E\left(\pi_{s}^{* *}\right)}{\partial \sigma_{\tilde{e}_{1}}^{2}}<0,
$$

$$
\frac{\partial E\left(\pi_{s}^{* *}\right)}{\partial \sigma_{e_{2}}^{2}}<0 .
$$


In addition, each member of the transnational supply chain may consider the total profit of the supply chain only on the premise of realizing their own profit maximization. Therefore, in centralized decision-making, the profits of the retailer, the supplier, and the manufacturer should not be less than those of decentralized decision-making. Only when this premise is met will they sign a revenue-sharing contract. Therefore, it can be as follows:

$$
\left\{\begin{array}{l}
E\left(\pi_{r}^{* *}\right)>\pi_{r}, \\
E\left(\pi_{s}^{* *}\right)>\pi_{s}, \\
\mathrm{EU}\left(\pi_{m}^{* *}\right)>\operatorname{EU}\left(\pi_{m}\right) .
\end{array}\right.
$$

According to equation (69), we can get the inequality of the revenue-sharing coefficient $\phi_{1}$ and $\phi_{2}$ as follows:

$$
\left\{\begin{array}{l}
\frac{\sqrt{\varphi_{1}}}{2 b+n+\rho\left(\varphi_{2}^{2} \alpha_{1}^{2} \sigma_{\epsilon_{1}}^{2}+\alpha_{2}^{2} \sigma_{\epsilon_{2}}^{2}\right)}>\frac{\sqrt{\left(\left(a-m-\lambda_{1}-\lambda_{2}-c_{r}-c_{m}\right) /(4 b+2 n)\right)}}{a-c_{r}-d-\lambda_{1}\left(1-\alpha_{1}\right)-\lambda_{2}\left(1-\alpha_{2}\right)-c_{m}} \\
\left(\left(\frac{\left((n / 2)+2 b \varphi_{1}-\left(1-\varphi_{2}\right) 2 b\right)}{\left[2 b+n+\rho\left(\varphi_{2}^{2} \alpha_{1}^{2} \sigma_{\epsilon_{1}}^{2}+\alpha_{2}^{2} \sigma_{\epsilon_{2}}^{2}\right)\right]^{2}} \times\left[a-c_{r}-m-\lambda_{1}\left(1-\alpha_{1}\right)-\lambda_{2}\left(1-\alpha_{2}\right)-c_{m}\right]-\frac{\left(1-\varphi_{2}\right) c_{r}}{2 b+n+\rho\left(\varphi_{2}^{2} \alpha_{1}^{2} \sigma_{\epsilon_{1}}^{2}+\alpha_{2}^{2} \sigma_{\epsilon_{2}}^{2}\right)}\right)>\frac{\left[n \times\left(\left(a-m-\lambda_{1}-\lambda_{2}-c_{r}-c_{m}\right) /(4 b+2 n)\right)-n \times\left(\left(a-m-\lambda_{1}-\lambda_{2}-c_{r}-c_{m}\right) /(4 b+2 n)\right)^{2}\right]}{\left[a-c_{r}-m-\lambda_{1}\left(1-\alpha_{1}\right)-\lambda_{2}\left(1-\alpha_{2}\right)-c_{m}\right]}\right) \\
\left(\frac{1}{2 b+n+\rho\left(\varphi_{2}^{2} \alpha_{1}^{2} \sigma_{\epsilon_{1}}^{2}+\alpha_{2}^{2} \sigma_{\epsilon_{2}}^{2}\right)} \times\left[a-\varphi_{2} c_{r}-m-\left(1-\alpha_{1}\right) \lambda_{1}-\left(1-\alpha_{2}\right) \lambda_{2}-c_{m}\right]-\frac{a-c_{r}-m-\lambda_{1}\left(1-\alpha_{1}\right)-\lambda_{2}\left(1-\alpha_{2}\right)-c_{m}}{\left[2 b+n+\rho\left(\varphi_{2}^{2} \alpha_{1}^{2} \sigma_{\epsilon_{1}}^{2}+\alpha_{2}^{2} \sigma_{\epsilon_{2}}^{2}\right)\right]^{2}} \times\left[b+n+b \varphi_{1}+2 b \varphi_{1} \varphi_{2}\right]\right) \\
>\frac{\left.\left(\left(a-c_{r}-m-\lambda_{1}-\lambda_{2}-(1 / 2) \times\left(\left(\lambda_{1}^{2} / \sigma_{\epsilon_{1}}^{2}\right)+\left(\lambda_{2}^{2} / \sigma_{\epsilon_{2}}^{2}\right)\right)\right) \times\left(\left(a-m-\lambda_{1}-\lambda_{2}-c_{r}-c_{m}\right) /(4 b+2 n)\right)-(2 b+n) \times\left(\left(a-m-\lambda_{1}-\lambda_{2}-c_{r}-c_{m}\right) /(4 b+2 n)\right)^{2}+\left(\lambda_{1}^{2} / \rho \sigma_{\epsilon_{1}}^{2}\right)+\left(\lambda_{2}^{2} / \rho \sigma_{\epsilon_{2}}^{2}\right)-c_{m}\right)\right)}{a-c_{r}-m-\lambda_{1}\left(1-\alpha_{1}\right)-\lambda_{2}\left(1-\alpha_{2}\right)-c_{m}} .
\end{array}\right.
$$

In this transnational supply chain, since the contracts are signed in the domestic currencies of the retailer and the supplier, the risks of import and export exchange rates are concentrated in the manufacturer. When each member of the transnational supply chain adopts the revenue-sharing contracts, the exchange rate risks are transmitted to the retailer and the supplier through the benchmark wholesale price of products, the benchmark selling price of raw materials, and the order quantity of the supply chain, thus affecting their expected profits. Due to the uncertainty of exchange rate fluctuations, all members of the supply chain are exposed to different degrees of exchange rate risks, and their expected profits are uncertain. At this time, the manufacturer should determine the appropriate positions in financial derivatives, select the optimal risk hedging ratio to reduce the exchange rate risks, and then obtain considerable expected profit. Therefore, the optimal wholesale price of products, the optimal selling price of raw materials, and the appropriate revenue-sharing coefficient are particularly important for centralized decision-making. On the premise of realizing the maximization of the total profit of the transnational supply chain, it should also maximize the profits of decision-makers.

\section{Simulation Analysis}

This section conducts simulation analysis on the aboveestablished models and relevant propositions, and the variables are set as $a=32, b=2, c_{r}=1, c_{m}=1, m=2, n=1, \lambda_{1}=2$, $\lambda_{2}=2, \rho=10, \varphi_{1}=0.5, \varphi_{2}=0.5$. Furthermore, suppose that the fluctuation range of import and export exchange rates borne by the manufacturer is $0 \sim 2$, and the values of $\sigma_{\tilde{\rho}_{1}}^{2}\left(\sigma_{1}^{2}\right)$ and $\sigma_{\tilde{e}_{2}}^{2}\left(\sigma_{2}^{2}\right)$ are $0.2,0.4,0.6, \ldots, 1.6,1.8,2$, respectively.

\subsection{Simulation Analysis on the Decentralized Supply Chain}

4.1.1. Simulation Analysis on Hedging Decision-Making Process of the Decentralized Supply Chain. According to equations (19) and (20), we can obtain the relationships between the manufacturer's risk exposure ratio, risk hedging ratio, and the fluctuations of the import and export exchange rates, as shown in Figure 1. Where the $x$-axis represents the fluctuations of the import and export exchange rates $\sigma_{1}^{2}\left(\sigma_{2}^{2}\right)$, the $y$-axis denotes the manufacturer's risk exposure ratio in Figure 1(a) $\alpha_{1}\left(\alpha_{2}\right)$ or risk hedging ratio in Figure 1(b) $1-\alpha_{1}\left(1-\alpha_{2}\right)$.

In Figure 1, in decentralized decision-making, the greater the fluctuations of import and export exchange rates are, the smaller the manufacturer's risk exposure ratio is. With the hypothesis of the manufacturer's risk-aversion, exchange rate risks are positively correlated with the risk hedging ratio. When the risk hedging ratio is higher, the influence of exchange rate fluctuations on the manufacturer's foreign exchange purchase expenditure and foreign exchange sales profit will be reduced, making the risk exposure ratio lower. Moreover, Figure 1 suggests that when the exchange rate risks are low (the value of exchange rate fluctuations is less than 0.8), the risk exposure ratio of the manufacturer shows a largely downward trend with the increase of exchange rate fluctuations. However, when the exchange rate risks are high (the value of exchange rate fluctuations is higher than 0.8 ), the risk exposure ratio shows a relatively gentle downward trend with the increase of exchange rate fluctuations. At this time, the manufacturer's risk exposure ratio can be controlled at around 0.1, indicating that the manufacturer may increase the positions in financial derivatives, making the risk hedging ratio increase to 0.9 , reducing the risk exposure ratio and its exchange 
losses. Therefore, when the manufacturer is exposed to higher risks of import and export exchange rates, it will increase the positions in financial derivatives to reduce the risk exposure ratio.

According to equations (18), (21), and (22), we can obtain the relationships between the benchmark wholesale price of products, the benchmark selling price of raw materials, the order quantity of the decentralized supply chain, and the fluctuations of import and export exchange rates, respectively, as shown in Figure 2. Where the $x$-axis represents the fluctuations of the import and export exchange rates $\sigma_{1}^{2}\left(\sigma_{2}^{2}\right)$, the $y$-axis denotes the benchmark wholesale price of products $\omega_{1}$, the benchmark selling price of raw materials $\omega_{2}$, and the order quantity of the decentralized supply chain $q$, respectively.

In Figure 2, under given conditions, both $\omega_{1}$ and $\omega_{2}$ move in a horizontal line parallel to the $x$-axis, and they are 22.6667 and 5.1667, respectively. This indicates that in decentralized decision-making, the benchmark wholesale price of products and the benchmark selling price of raw materials given by the manufacturer are fixed values and not affected by exchange rate risks. Furthermore, Figure 2 displays that as the fluctuations of import and export exchange rates increase, the trend of $q$ is a horizontal line parallel to the $x$-axis. According to Section 3.1.2, the order quantity of the supply chain is equal to the order quantity of products and the supply of raw materials, respectively, namely, $q=q_{1}=q_{2}$. Therefore, the order quantity of the retailer and the supply quantity of the supplier are constant, and they do not change in decentralized decision-making. This shows that in the decentralized transnational supply chain, the final product order quantity of the retailer and raw material sales quantity of the supplier are not affected by the risks of import and export exchange rates.

\subsubsection{Simulation Analysis on the Expected Profits of} Decision-Makers in the Decentralized Supply Chain. According to equations (26) and (27), in decentralized decision-making, the relationships between the manufacturer's expected profit, profit variance, and the fluctuations of import and export exchange rates can be obtained, as shown in Figures 3 and 4 . Where the $x$-axis represents the fluctuations of the export exchange rate $\sigma_{1}^{2}$, the $y$-axis denotes the fluctuations of the import exchange rate $\sigma_{2}^{2}$, and the $z$-axis is the manufacturer's expected profit $E\left(\pi_{m}\right)$ (Figure 3 ) or profit variance $\operatorname{Var}\left(\pi_{m}\right)$ (Figure 4 ).

In Figure 3, in decentralized decision-making, under the hedging strategy for exchange rate risks, the manufacturer's expected profit decreases slightly with the increase of the fluctuations of import and export exchange rates. When the value of the fluctuations of import and export exchange rates is 2, the manufacturer is faced with higher risks of import and export exchange rates. Therefore, since the manufacturer is risk-averse, it may increase the positions in financial derivatives. When the exchange rate risks are higher, the manufacturer's risk exposure ratio will be lower. That is, the risk hedging ratio will be larger. In other words, the manufacturer may increase the positions in financial derivatives to hedge higher exchange risks. For a risk-averse manufacturer, the above results are consistent with practice. Figure 4 illustrates that, in decentralized decision-making, if the manufacturer hedges the exchange rate risks, its profit variance will decrease with the increase of the fluctuations of import and export exchange rates. The higher the risks of import and export exchange rates, the greater the risk hedging ratio of the manufacturer, and the impact of exchange rate fluctuations on its foreign exchange sales profit and foreign exchange purchase expenditure will be smaller. In other words, under the hedging strategy for exchange rate risks, the risk exposure ratio of the manufacturer will be continuously reduced. Therefore, the manufacturer's profit variance decreases as the fluctuations of import and export exchange rates increase.

According to equations (24) and (25), the relationships between the expected profits of the retailer and the supplier and the fluctuations of import and export exchange rates in decentralized decision-making can be obtained, as shown in Figure 5. Where the $x$-axis represents the fluctuations of the import and export exchange rates $\sigma_{1}^{2}\left(\sigma_{2}^{2}\right)$, the $y$-axis denotes the expected profits of the retailer $E\left(\pi_{r}\right)$ and the supplier $E\left(\pi_{s}\right)$.

In Figure 5, in decentralized decision-making, the expected profits of the retailer and the supplier are 8.6806 and 4.3403 , respectively. They are fixed values that are not affected by the fluctuations in the import and export exchange rates. As mentioned above, in decentralized decisionmaking, the benchmark wholesale price of the retailer's products, the benchmark selling price of the supplier's raw materials, and the order quantity of the supply chain are fixed values, which are not affected by the exchange rate risks (Figure 2). Therefore, this indicates that the exchange rate risks are not transmitted in the decentralized transnational supply chain so that the expected profits of the retailer and the supplier are little affected by the exchange rate risks.

\subsection{Simulation Analysis on the Centralized Supply Chain.} In the centralized supply chain, we examine the influence of bilateral exchange rate risks and the manufacturer's financial hedging strategies on the profit and decision-making process of each member in the supply chain under the incentive mechanism of exchange rate risk hedging.

4.2.1. Simulation Analysis on Hedging Decision-Making Process of the Centralized Supply Chain. This section conducts simulation analysis on the decision-making process of exchange rate risk hedging in the centralized transnational supply chain under the wholesale price agreements and the revenue-sharing contracts, respectively.

(1) Simulation Analysis on the Hedging Decision-Making Process of the Centralized Supply Chain under Wholesale Price Agreements. According to equations (44) and (45), the relationships between the manufacturer's risk exposure ratio and the fluctuations of import and export exchange rates under the wholesale price agreements can be obtained, as shown in Figure 6 . Where the $x$-axis represents the 

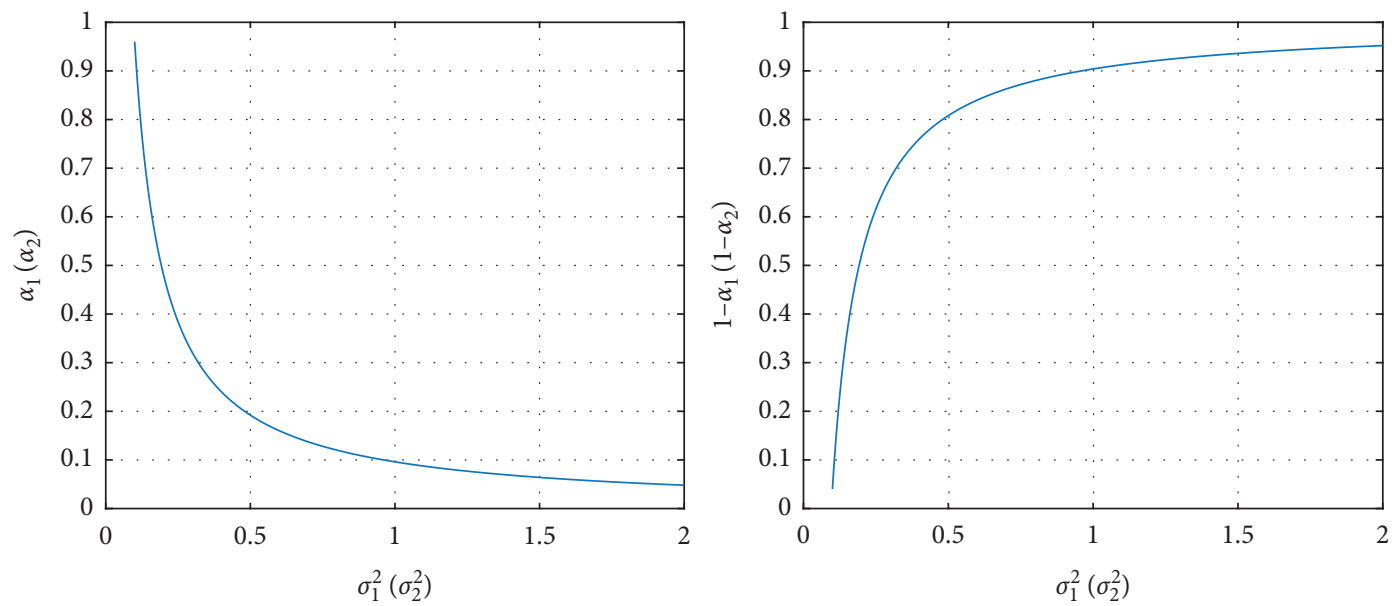

FIGURE 1: The manufacturer's risk exposure ratio and risk hedging ratio in decentralized decision-making.

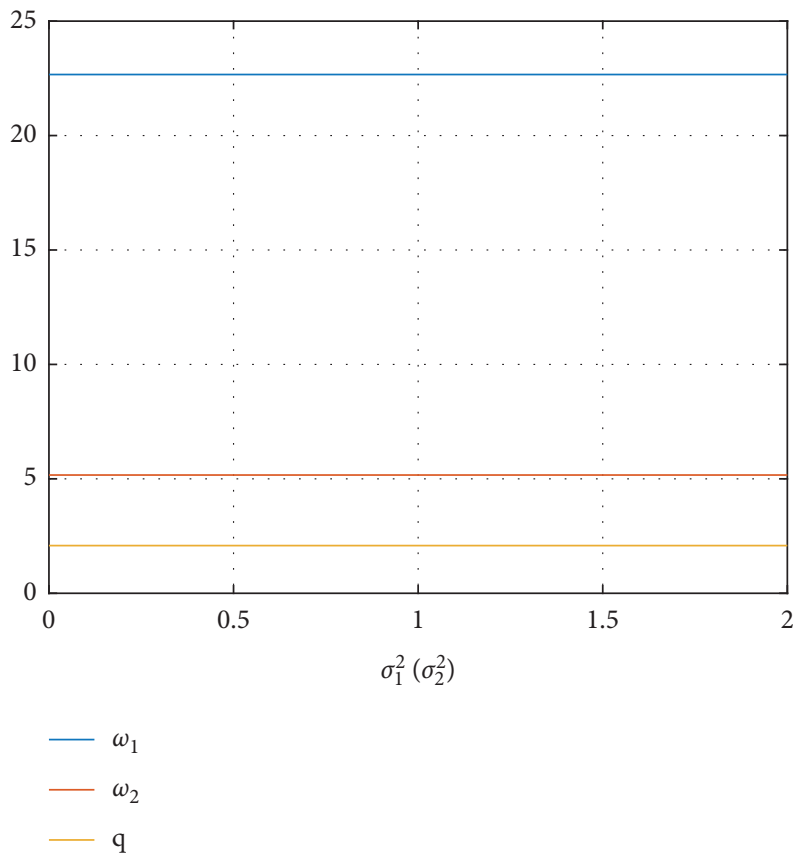

FIGURE 2: The benchmark wholesale price of products, the benchmark selling price of raw materials, and order quantity of supply chain in decentralized decision-making.

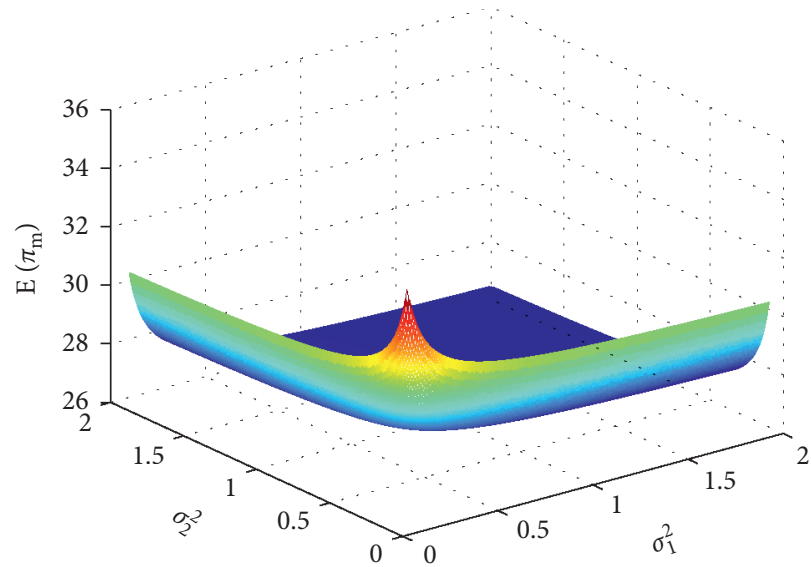

FIGURE 3: The manufacturer's expected profit in decentralized decision-making. 


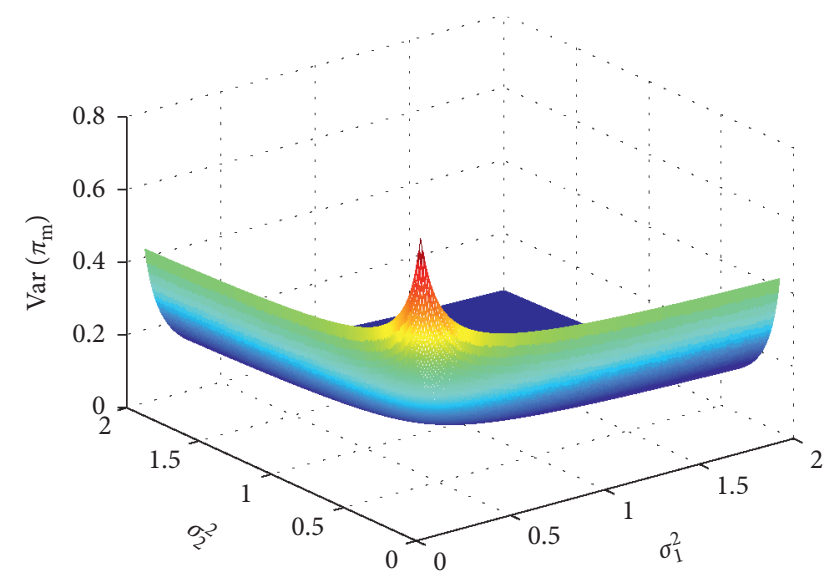

FIgURE 4: The manufacturer's profit variance in decentralized decision-making.

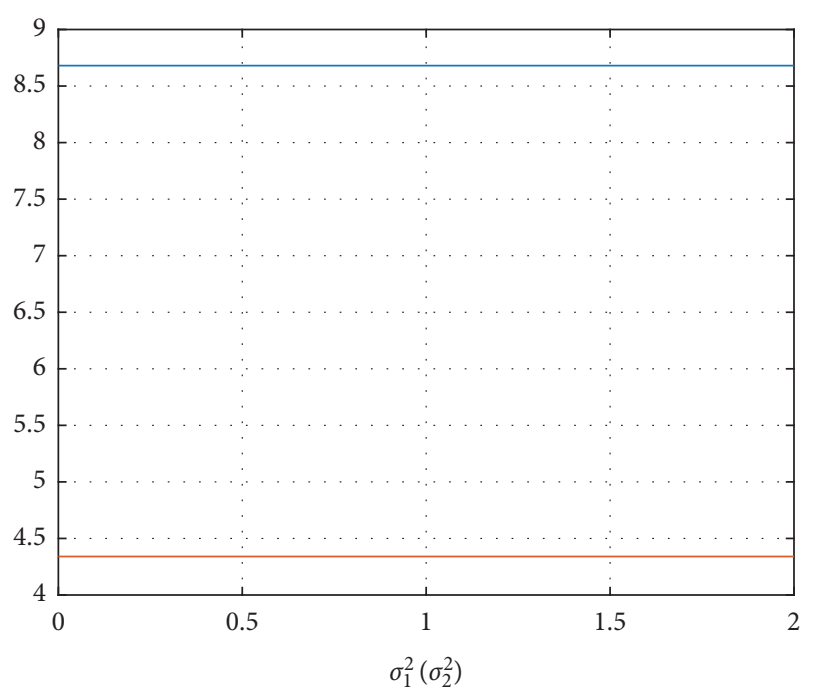

$-\mathrm{E}\left(\pi_{\mathrm{r}}\right)$

$-\mathrm{E}\left(\pi_{\mathrm{s}}\right)$

FIGURE 5: The expected profits of the retailer and the supplier in decentralized decision-making.

fluctuations of the export and import exchange rates $\sigma_{1}^{2}\left(\sigma_{2}^{2}\right)$, the $y$-axis denotes the risk exposure ratio $\left(\alpha\right.$ and $\left.\alpha^{*}\right)$ and the risk hedging ratio $\left(1-\alpha\right.$ and $\left.1-\alpha^{*}\right)$. Among them, $\alpha(1-$ $\left.\alpha^{*}\right)$ and $\alpha^{*}\left(1-\alpha^{*}\right)$ are the manufacturer's risk exposure ratio (risk hedging ratio) in decentralized decision-making and wholesale price agreements, respectively. According to Figure 6, the manufacturer's risk exposure ratio decreases with the increase of import and export exchange rate fluctuations for decentralized decision-making and wholesale price agreements.

Furthermore, in decentralized decision-making and wholesale price agreements, the relationships between the fluctuations of export and import exchange rates, order quantity of the supply chain, and the risk exposure ratio of the manufacturer are shown in Table 1 . When the value of fluctuations of import and export exchange rates is 0.2 , the

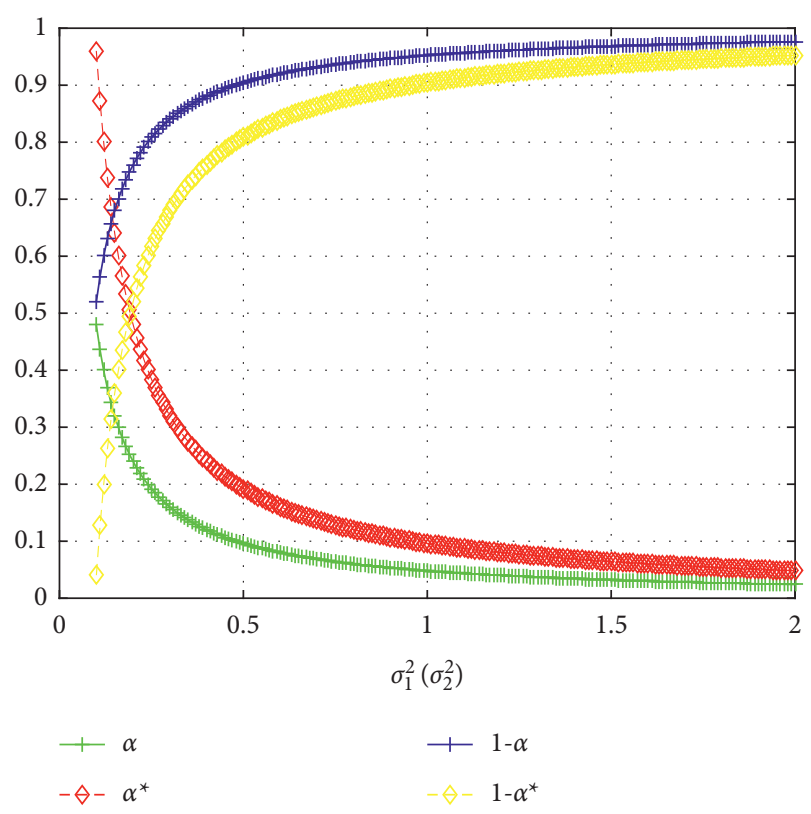

FIGURE 6: The risk exposure ratio and risk hedging ratio under the wholesale price agreement.

manufacturer's risk exposure ratio and risk hedging ratio are 0.24 and 0.76 in decentralized decision-making, while those are 0.48 and 0.52 under the wholesale price agreements. This shows that, compared with decentralized decision-making, when all members of the transnational supply chain adopt the wholesale price agreements, the hedging strategies of the manufacturer have changed from the perspective of maximizing the total profit of the supply chain. The manufacturer's positions in financial derivatives may be reduced, the risk hedging ratio will be reduced, and the risk exposure ratio will eventually increase.

We take the incentive coefficient of risk hedging $l_{1}=l_{2}=0.2,0.4,0.6,0.8$. According to equation (54), the relationships between the wholesale price of the retailer's products, the selling price of the supplier's raw materials, and the exchange rate fluctuations under the wholesale price agreements can be obtained, as illustrated by Figures 7 and 8 . In Figure 7 , the $x$-axis represents the fluctuations of the export exchange rate $\sigma_{1}^{2}$, and the $y$-axis denotes the benchmark wholesale price of the retailer's products $\omega_{1}^{*}$. In Figure 8 , the $x$-axis represents the fluctuations of the import exchange rate $\sigma_{2}^{2}$, and the $y$-axis denotes the benchmark wholesale price of raw materials for the supplier $\omega_{2}^{*}$.

Figure 7 illustrates that the benchmark wholesale price of the retailer's products decreases with the increase of export exchange rate fluctuations and increases as the incentive coefficients of risk hedging increase. The higher the manufacturer's risk hedging ratio is, the greater the benchmark wholesale price of the retailer's products will be. Meanwhile, the stronger the incentive for the retailer to incentivize the manufacturer to hedge export exchange rate risk, the greater the retailer's benchmark wholesale price. In Figure 8, the benchmark selling price of the supplier's raw materials increases with the rise of import exchange rate fluctuations and decreases with the increase of the incentive coefficient of 
TABLE 1: Supply chain order quantity and the manufacturer's risk exposure ratio in decentralized decision-making and wholesale price agreements.

\begin{tabular}{|c|c|c|c|c|c|c|c|c|c|c|}
\hline \multirow{2}{*}{$q, \alpha$} & \multicolumn{10}{|c|}{$\sigma^{2}$} \\
\hline & 0.2 & 0.4 & 0.6 & 0.8 & 1 & 1.2 & 1.4 & 1.6 & 1.8 & 2 \\
\hline$q$ & 2.083 & 2.083 & 2.083 & 2.083 & 2.083 & 2.083 & 2.083 & 2.083 & 2.083 & 2.083 \\
\hline$q^{*}$ & 4.167 & 4.167 & 4.167 & 4.167 & 4.167 & 4.167 & 4.167 & 4.167 & 4.167 & 4.167 \\
\hline$\alpha\left(\alpha_{1}, \alpha_{2}\right)$ & 0.240 & 0.120 & 0.080 & 0.060 & 0.048 & 0.040 & 0.034 & 0.030 & 0.027 & 0.024 \\
\hline$\alpha^{*}\left(\alpha_{1}^{*}, \alpha_{2}^{*}\right)$ & 0.480 & 0.240 & 0.160 & 0.120 & 0.096 & 0.080 & 0.069 & 0.060 & 0.053 & 0.048 \\
\hline
\end{tabular}

Notes: $\sigma^{2}$ represents the values of fluctuations of export and import exchange rates. $q(\alpha)$ and $q^{*}\left(\alpha^{*}\right)$ denote the order quantity (the manufacturer's risk exposure ratio) in decentralized decision-making and wholesale price agreements, respectively.

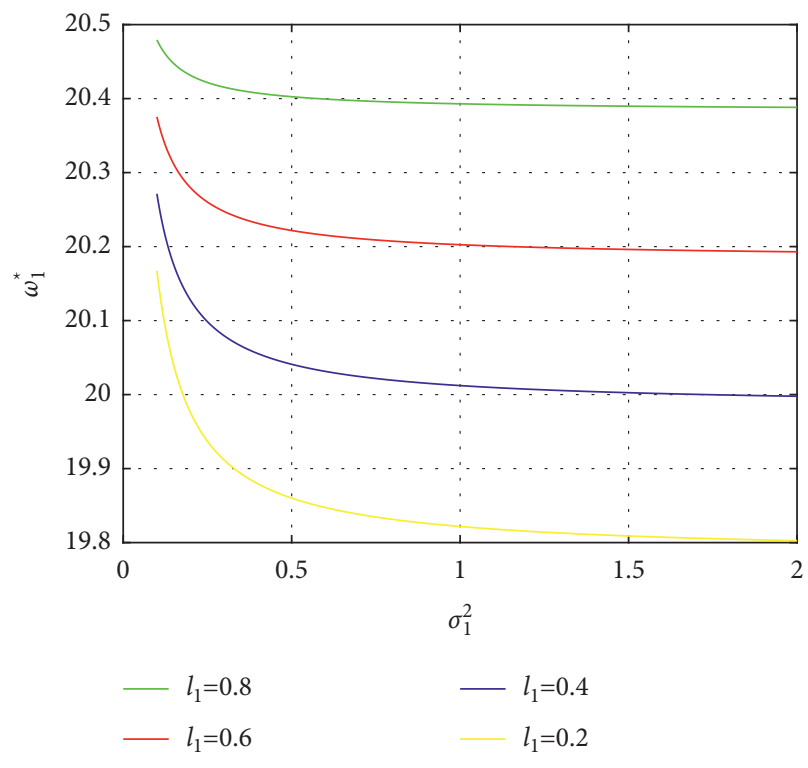

Figure 7: The benchmark wholesale price of the retailer's products under the wholesale price agreement.

risk hedging. The higher the risk hedging ratio of the manufacturer, the stronger the incentive for the supplier to incentivize the manufacturer to hedge import exchange rate risk, and the smaller the benchmark selling price of raw materials for the supplier. In addition, combined with Figure 2, we find that $\omega_{1}^{*}<20.58<\omega_{1}=22.67$ and $\omega_{2}^{*}>6.21>\omega_{2}=5.67$. Therefore, compared with decentralized decision-making, under the wholesale price agreement, the benchmark wholesale price of the retailer's products is lower, and the benchmark selling price of the supplier's raw materials is higher.

According to equation (43), the relationships between the order quantity of the supply chain and the fluctuations of import and export exchange rates in the wholesale price agreements can be obtained, as shown in Figure 9. Where the $x$-axis represents the fluctuations of the export and import exchange rates $\sigma_{1}^{2}\left(\sigma_{2}^{2}\right)$, the $y$-axis denotes the order quantity $\left(q\right.$ or $\left.q^{*}\right)$ of the supply chain in decentralized decisionmaking or wholesale price agreement. In Figure 9, the trend of order quantity $q^{*}$ of the supply chain under the wholesale price agreements is a horizontal line parallel to the $x$-axis. According to Section 3.1.2, $q=q_{1}=q_{2}$. Therefore, the order quantity of the retailer's products, the supply quantity of the supplier's raw materials, and the order quantity of the supply

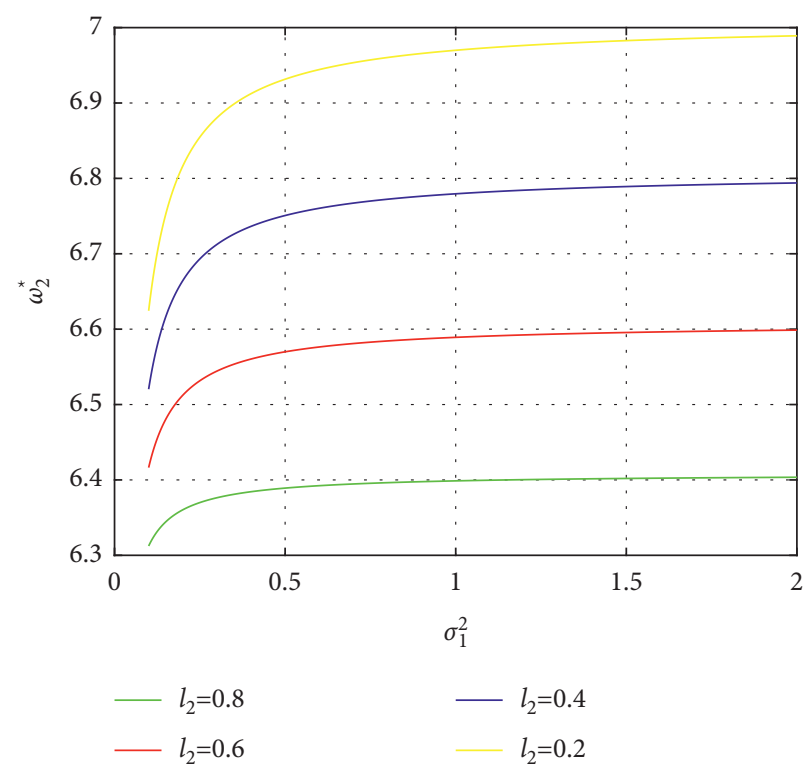

FIgURE 8: The benchmark selling price of the supplier's raw materials under the wholesale price agreement.

chain are fixed values and do not change with the exchange rate fluctuations.

Figure 9 also illustrates that the $q$ curve is always below the $q^{*}$ curve. Furthermore, Table 1 reports that as the fluctuations of import and export exchange rates $\sigma^{2}$ increase, $q$ and $q^{*}$ are always 2.803 and 4.167 , respectively, and the latter is greater than the former. Therefore, the above results suggest that compared with decentralized decision-making, the order quantity of the transnational supply chain is improved in centralized decision-making.

(2) Simulation Analysis on the Hedging Decision-Making Process of the Centralized Supply Chain under Revenue-Sharing Contract. We set the manufacturer's import risk exposure ratio $\alpha_{1}$ as 0.2 and 0.4 , and the export risk exposure ratio $\alpha_{2}$ as 0.6 and 0.8 , respectively. That is, the hedging ratios of import and export risk are $0.2,0.4$ and $0.6,0.8$, respectively. Furthermore, since the manufacturer is risk-averse, we set the manufacturer's risk exposure ratio as 0.2 , that is, the risk hedging ratio as 0.8 . According to equation (62), the relationships of the benchmark wholesale price of products, the benchmark selling price of raw materials, and the fluctuations of import and export exchange rates under the revenue-sharing contracts can be obtained, as shown in Figures 10 and 11 . Where the $x$-axis 


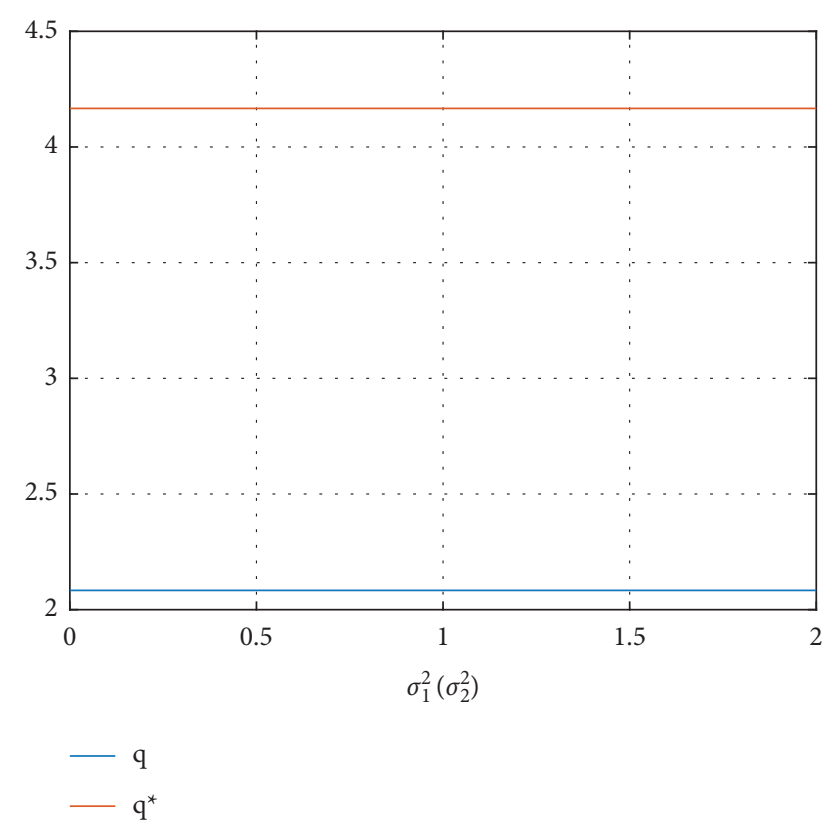

FIGURE 9: Supply chain order quantity under the wholesale price agreement.

represents the fluctuations of the export exchange rate $\sigma_{1}^{2}$, the $y$-axis denotes the fluctuations of the import exchange rate $\sigma_{2}^{2}$, and the $z$-axis is the benchmark wholesale price of products $\omega_{1}^{* *}$ (Figure 10) or the benchmark selling price of raw materials $\omega_{2}^{* *}$ (Figure 11) under the revenue-sharing contract.

In Figure 10, the benchmark wholesale price of products increases with the rise of exchange rate fluctuations. And the fluctuations of the import exchange rate have a greater impact on its wholesale price compared with the import exchange rate. In Figure 11, under the revenue-sharing contract, the benchmark selling price of the supplier's raw materials decreases as the exchange rate fluctuations increase. This is probably because that there are revenuesharing contracts among members in centralized decisionmaking, making the benchmark wholesale price of the products and the benchmark selling price of the raw materials affected by exchange rate risks.

According to equation (63), the relationships between the order quantity of the centralized supply chain and the fluctuations of import and export exchange rates under the revenue-sharing contracts can be obtained, as shown in Figure 12. Where the $x$-axis represents the fluctuations of the export exchange rate $\sigma_{1}^{2}$, the $y$-axis denotes the fluctuations of the import exchange rate $\sigma_{2}^{2}$, and the $z$-axis is the order quantity $q$ of the supply chain. In Figure 12, as the risk exposure ratio $\left(\alpha_{1}\right.$ and $\left.\alpha_{2}\right)$ of the manufacturer increases, the optimal order quantity of the retailer and the optimal supply quantity of the supplier rise. That is, the larger the risk hedging ratio of the manufacturer, the smaller the retailer's optimal order quantity and the supplier's optimal supply quantity will be. Furthermore, with the increase of exchange rate fluctuations, the supply quantity of the transnational supply chain will decrease. Therefore, under the revenue-

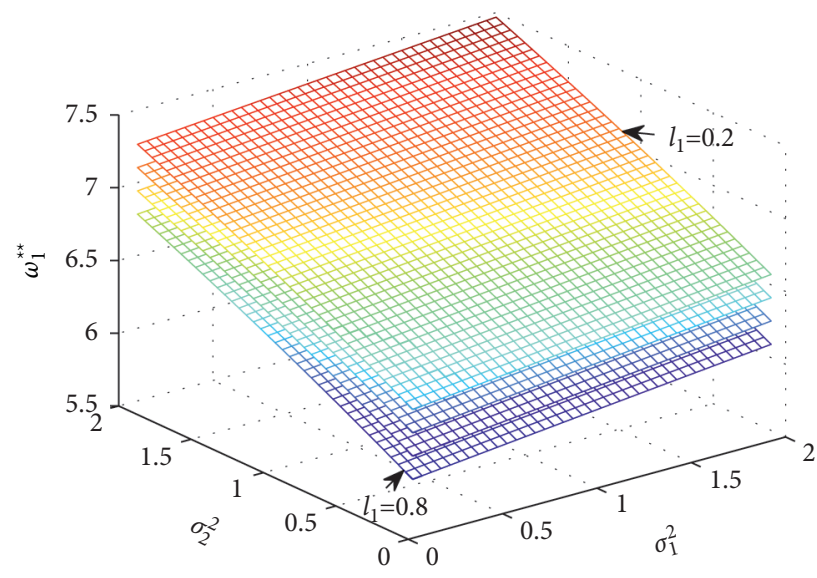

FIgURE 10: The benchmark wholesale price of the retailer's products under the revenue-sharing contract.

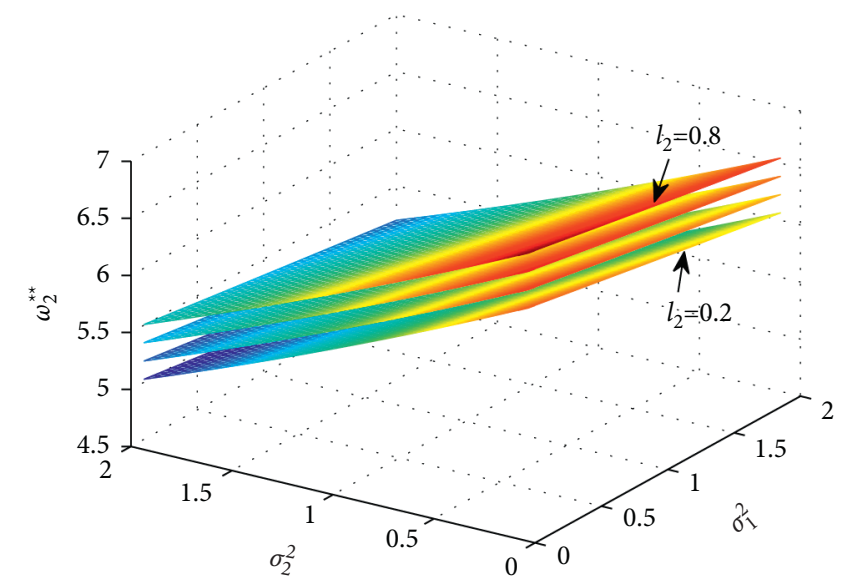

FIGURE 11: The benchmark selling price of the supplier's raw materials under the revenue-sharing contract.

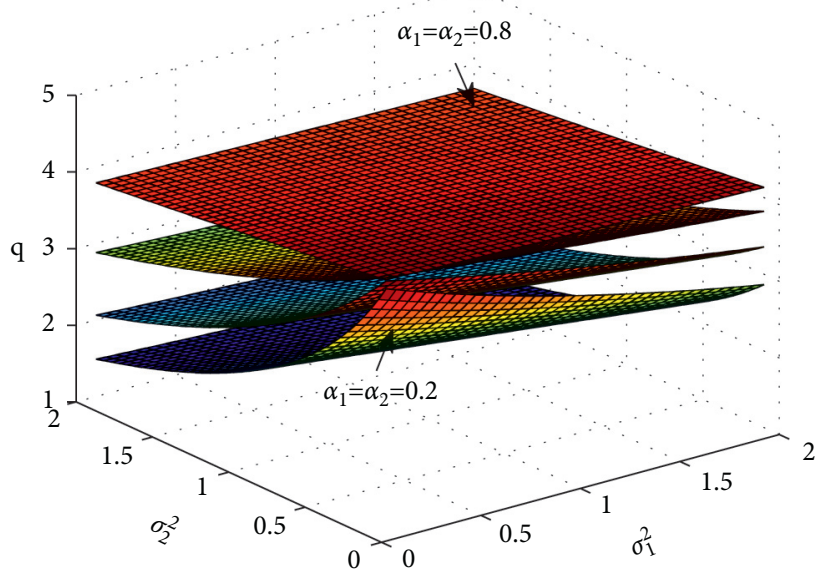

FIGURE 12: Supply chain order quantity under the revenue-sharing contract.

sharing contract, the order quantity of the transnational supply chain is inversely related to the exchange rate risks and the hedging ratio of the manufacturer. Therefore, in 
centralized decision-making, under the revenue-sharing contract, the order quantity of the transnational supply chain is uncertain, so all decision-makers need to weigh order quantity and exchange rate risks.

4.2.2. Simulation Analysis on the Expected Profits of Decision-Makers in the Centralized Supply Chain. This section simulates and analyzes the expected profits of decision-makers in the centralized supply chain under the wholesale price agreements and the revenue-sharing contract, respectively.

(1) Simulation Analysis on the Expected Profits of DecisionMakers in the Centralized Supply Chain under Wholesale Price Agreement. According to equations (49) and (50), we can obtain the relationships of the expected profits of the retailer and the supplier and the fluctuations of import and export exchange rates under the wholesale price agreement, as displayed in Figures 13 and 14. In Figure 13, the $x$-axis represents the fluctuations of the export exchange rate $\sigma_{1}^{2}$, the $y$-axis denotes the retailer's expected profit $E\left(\pi_{r}^{*}\right)$. In Figure 14, the $x$-axis represents the fluctuations of the import exchange rate $\sigma_{2}^{2}$, and the $y$-axis denotes the supplier's expected profit $E\left(\pi_{s}^{*}\right)$. As shown in Figures 13 and 14, in centralized decision-making, when the wholesale price agreements are adopted, the retailer's expected profit only decreases with the increase of export exchange rate fluctuations, while the supplier's expected profit only decreases with the increase of import exchange rate fluctuations. In centralized decision-making, under the effect of the incentive mechanism of exchange rate risk hedging, the benchmark wholesale price of the retailer's products is affected by export exchange rate risks, so its expected profit is influenced by export exchange rate fluctuations. Similarly, for the supplier, the benchmark selling price of raw materials is affected by the import exchange rate risks, so its expected profit is subject to the fluctuations of the import exchange rate.

(2) Simulation Analysis on the Expected Profits of DecisionMakers in the Centralized Supply Chain under RevenueSharing Contract. According to equations (64) and (65), we can obtain the relationships of the manufacturer's expected profit and profit variance and the fluctuations of import and export exchange rates under the revenue-sharing contract, as shown in Figures 15 and 16. Where the $x$-axis represents the fluctuations of the export exchange rate $\sigma_{1}^{2}$, the $y$-axis denotes the fluctuations of the import exchange rate $\sigma_{2}^{2}$, and the $z$-axis is the manufacturer's expected profit $E\left(\pi_{m}^{* *}\right)$ (Figure 15) or profit variance $\operatorname{Var}\left(\pi_{m}^{* *}\right)$ (Figure 16) under the revenue-sharing contract.

In Figure 15, when the positions in financial derivatives are fixed, that is, the risk hedging ratio remains unchanged. The manufacturer's expected profit will increase with the rise of the fluctuations of import and export exchange rates. Meanwhile, import exchange rate fluctuations have a much greater influence on the manufacturer's expected profit than the export exchange rate. When the manufacturer's risk

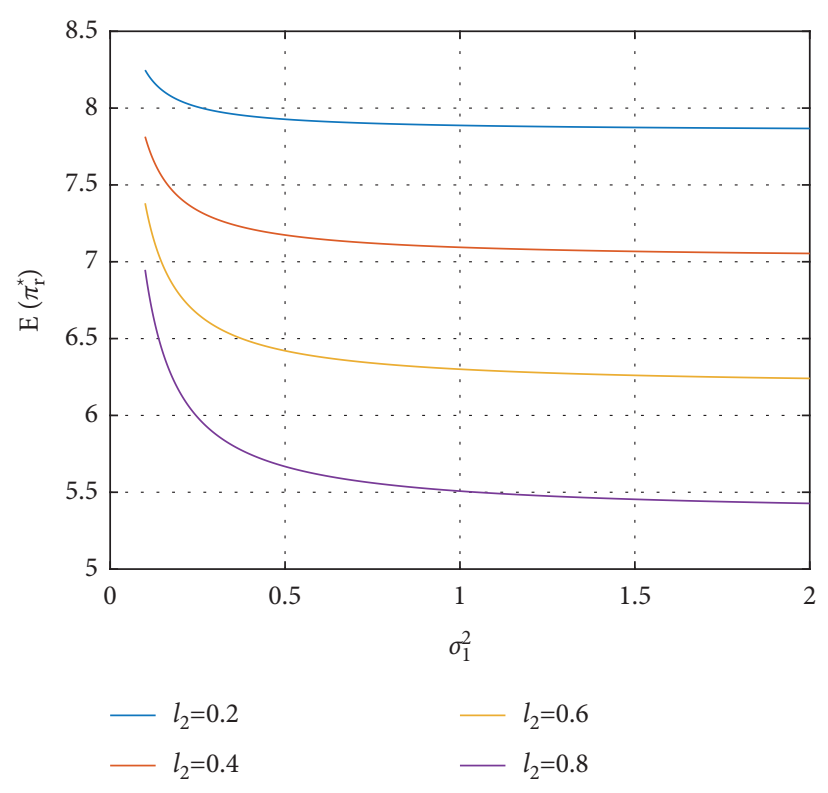

FIGURE 13: The retailer's expected profit under the wholesale price agreement.

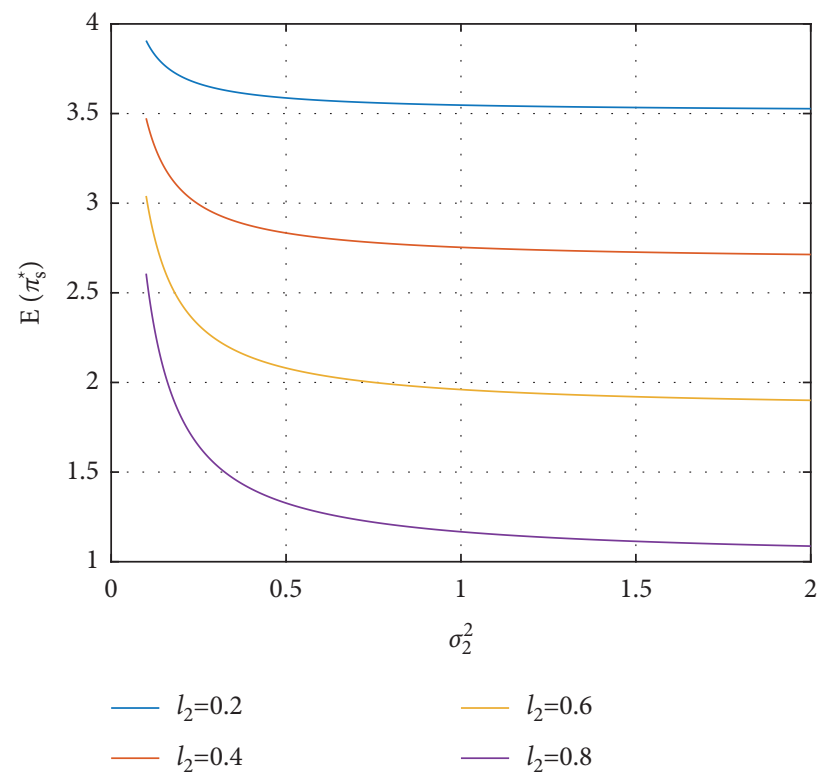

FIgURE 14: The supplier's expected profit under the wholesale price agreement.

hedging ratio increases, its expected profit decreases continuously. In Figure 16, the manufacturer's profit variance decreases with the increase of exchange rate fluctuations. Compared with the import exchange rate, the export exchange rate has a greater impact on the profit variance. According to the statistical results in Figures 4 and 16, the manufacturer's profit variance in centralized decisionmaking is larger than that of decentralized decision-making, but the difference between them is small. Under the revenuesharing contract, the manufacturer can take a higher ratio of risk hedging. When the risk hedging ratio is greater than 0.8 , 


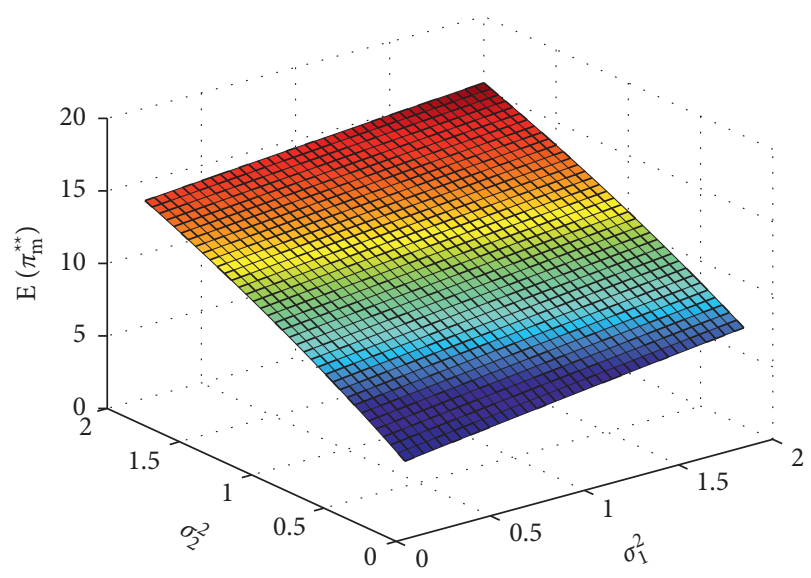

FIGURE 15: The manufacturer's expected profit under the revenuesharing contract.

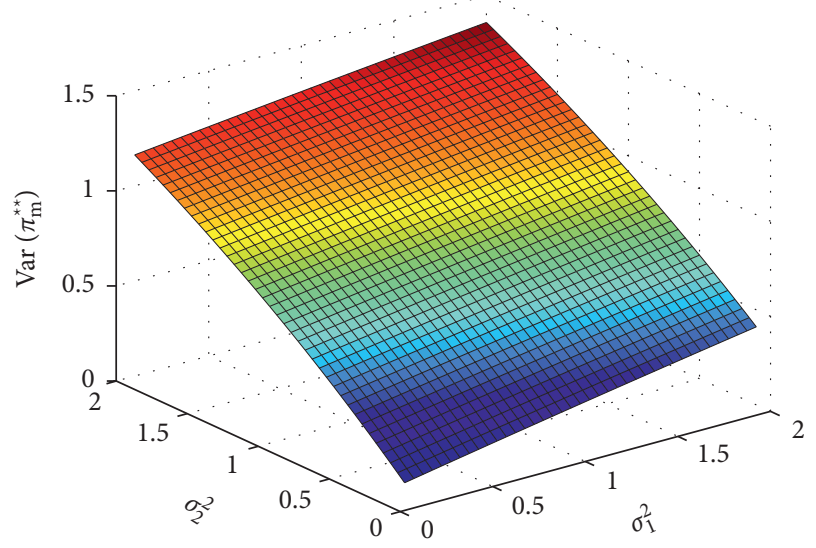

FIGURE 16: The manufacturer's profit variance under the revenuesharing contract.

the manufacturer's profit variance will be smaller than that of decentralized decision-making. That is, the influence of exchange rate fluctuations on the manufacturer's expected profit will be continuously reduced.

We further set the risk hedging ratio as 0.9 , that is, increase the positions in financial derivatives so that the risk exposure ratio is reduced to 0.1. Furthermore, under the revenue-sharing contract, the manufacturer's profit variance comparison between decentralized and centralized decisionmaking is shown in Table 2.

Table 2 suggests that when the exchange rate risk hedging ratio of the manufacturer is 0.9 , the manufacturer's profit variance in centralized decision-making is smaller than that in decentralized decision-making. When the value of fluctuations of import and export exchange rates is less than or equal to 1.6, the manufacturer's profit variance in centralized decision-making is much less than that in decentralized decision-making. When the value of the exchange rate fluctuations is greater than 1.6 and the value is 1.8 or 2 , the profit variance of centralized decision-making is slightly greater than that of decentralized decision-making. For example, when the values of fluctuations of import and export exchange rates are 2 and 1.8, respectively, the manufacturer's profit variance in decentralized decisionmaking and centralized decision-making are 0.380122 and 0.382313 , with a difference of only 0.002191 . When the values of the fluctuations of import and export exchange rates are both 2, the manufacturer's profit variance in decentralized decision-making and centralized decisionmaking is 0.400360 and 0.412902 , respectively, and the difference is 0.012542 . Since the manufacturer is risk-averse, it may be more inclined to increase the positions in financial derivatives and may set the risk hedging ratio as 0.9 , but its expected profit will be reduced. Thus, the manufacturer needs to balance the hedging strategy for exchange rate risks with its expected profit.

According to equations (66) and (67), we can obtain the relationships between the expected profits of the retailer and the supplier and the fluctuations of import and export exchange rates, respectively, as shown in Figures 17 and 18. Where the $x$-axis represents the fluctuations of the export exchange rate $\sigma_{1}^{2}$, the $y$-axis denotes the fluctuations of the import exchange rate $\sigma_{2}^{2}$, and the $z$-axis is the retailer's expected profit $E\left(\pi_{r}^{* *}\right)$ (Figure 17) or the supplier's expected profit $E\left(\pi_{s}^{* *}\right)$ (Figure 18) under the revenue-sharing contract.

As shown in Figures 17 and 18, the expected profits of the retailer and the supplier decrease with the increase of the fluctuations of import and export exchange rates. Compared with the export exchange rate, the fluctuations of the import exchange rate have a greater impact on their expected profit. This suggests that for the retailer and supplier, unlike decentralized decision-making and wholesale price agreements, when supply chain members adopt the revenuesharing contract, the expected profits of both are affected by the risks of import and export exchange rates, and the import exchange rate risks have a greater influence on the profits of the retailer and the supplier compared with export exchange rate risks. In addition, the retailer's expected profit is 8.6806 in decentralized decision-making (Figure 5), while that is greater than 8.6806 under the revenue-sharing contracts (Figure 17). Compared with decentralized decision-making, the supplier's expected profit under the revenue-sharing contracts also increases significantly. Therefore, for decision-makers in the transnational supply chain, centralized decision-making is better than decentralized decision-making.

\section{Managerial Implications}

This section presents management implications based on Propositions 1-6 and simulation analysis results above.

(i) Propositions 1 and 2 show that, in decentralized decision-making, when the fluctuation risks of import and export exchange rates increase, the manufacturer can raise the financial hedging ratio of exchange rate risks to lower variance of expected profits. But that only applies if the manufacturer is risk-averse. If the manufacturer is risk preference or neutral, this may make it impossible for the members 
TABLE 2: The manufacturer's profit variance comparison between decentralized and centralized decision-making when the risk hedging ratio is 0.9 .

\begin{tabular}{|c|c|c|c|c|c|c|c|c|c|c|c|}
\hline \multirow{2}{*}{\multicolumn{2}{|c|}{$\sigma_{\widetilde{e}_{2}}^{2}$}} & \multicolumn{10}{|c|}{$\sigma_{\widetilde{e}_{1}}^{2}$} \\
\hline & & 0.2 & 0.4 & 0.6 & 0.8 & 1 & 1.2 & 1.4 & 1.6 & 1.8 & 2 \\
\hline \multirow{2}{*}{0.2} & & & 66 & 04 & 0.305556 & 0.304219 & 0.3 & 0.3 & 84 & 0.2 & 19 \\
\hline & & 32 & 0.053 & 0.061998 & 0.070738 & 0.079449 & 0.088131 & 0.096784 & 0.105408 & 0.114004 & 0.122571 \\
\hline \multirow{2}{*}{0.4} & Decentralized & & & 309234 & 307881 & 306540 & & 303895 & 302591 & 0.301298 & \\
\hline & & & & & 0.105 & & & 0.131 & 0.13 & 0.148103 & \\
\hline \multirow{2}{*}{0.6} & Decen & 0316 & 0315 & 34 & 5 & 60 & 0.3 & 0 & 0.307 & 0.30 & \\
\hline & & & & & & & & & 83 & & \\
\hline \multirow{2}{*}{0.8} & Dec & & & & & & & & & & \\
\hline & & & & 35 & $0.1^{\prime}$ & & 0.19 & 0.19 & 03 & & \\
\hline \multirow[b]{2}{*}{1} & & & & & & & & & & & \\
\hline & Cent & 755 & 0.19 & 0.198414 & 0.206703 & 0.214964 & 0.223198 & 0.231405 & 0.239585 & 0.247737 & 0.255864 \\
\hline \multirow{2}{*}{1.2} & Decentralized & 345427 & 0.343923 & 0.342433 & 0.340957 & 0.339493 & 0.338043 & 0.336606 & 0.335181 & 0.333770 & 0.332370 \\
\hline & & & & & & & & & 0.272036 & & \\
\hline \multirow{2}{*}{1.4} & Decentralized & & & 0.356544 & & 0.353493 & 0.351988 & & 0.349017 & 0.347551 & 0.346099 \\
\hline & & 0.247737 & 0.255864 & 0.263963 & 0.272036 & 0.280082 & 0.288102 & 0.296095 & 0.304063 & 0.312004 & 0.319919 \\
\hline \multirow{2}{*}{1.6} & & & & & & & & & & & \\
\hline & Decentralized & 0.280082 & 0.288102 & 0.296095 & 0.304063 & 0.312004 & 0.319919 & 0.327808 & 0.335671 & 0.343509 & 0.351321 \\
\hline \multirow{2}{*}{1.8} & & & 202012 & 0.391524 & 0.389852 & & & 0.384923 & 0.383308 & 0.381708 & \\
\hline & Decentralized & & & & & & 0.351321 & 0.359107 & 0.366868 & & 0.382313 \\
\hline \multirow{2}{*}{2} & & & & & & & & & & & \\
\hline & Centralized & 0.343509 & 0.351321 & 0.359107 & 0.366868 & 0.374603 & 0.382313 & 0.389998 & 0.397658 & 0.405293 & 0.412902 \\
\hline
\end{tabular}

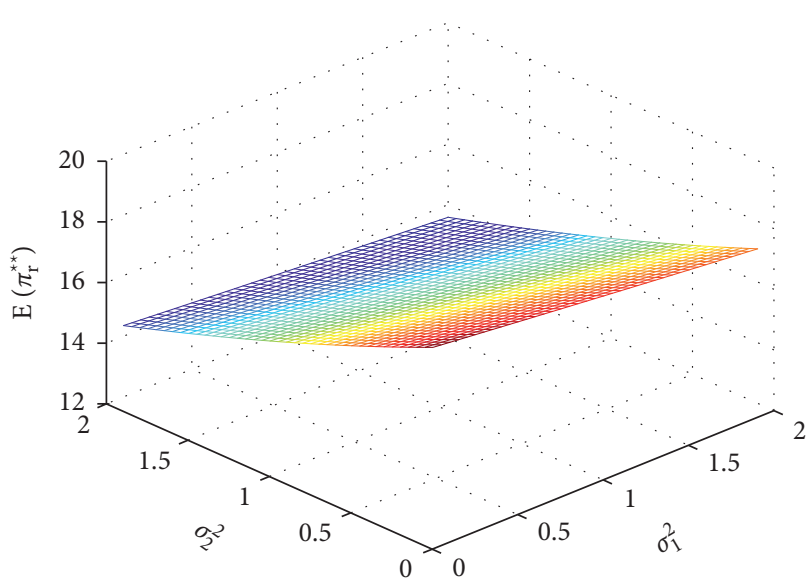

FIGURE 17: The retailer's expected profit under the revenue-sharing contract.

to cooperate effectively and form a supply chain. When the import and export foreign exchange risks increase, if the manufacturer adopts financial risk hedging strategies to reduce the risk exposure ratio, this may decrease its expected profits. Therefore, the manufacturer with risk preference or neutral may not use hedging strategies to avoid exchange rate risks, thus leading to the inability of the supplier, the retailer, and the manufacturer to realize decentralized decision-making.

(ii) Proposition 3 shows that in centralized decisionmaking, if the manufacturer, the retailer, and the supplier adopt the wholesale price agreement, they will decide with the goal of "maximizing the overall

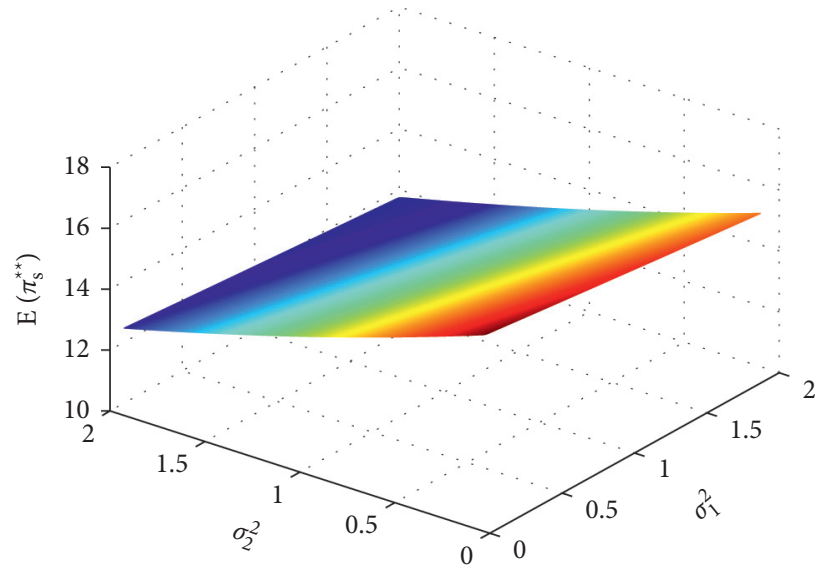

Figure 18: The supplier's expected profit under the revenuesharing contract.

profits." Therefore, to obtain higher overall profit and avoid more exogenous exchange rate risks, supply chain decision-makers will have stronger motivation to increase the order quantity and increase the proportion of exchange rate risk hedging. As a result, members in the supply chain can sign wholesale price agreements to increase order quantity and stimulate risk hedging.

(iii) Proposition 4 suggests that, under the wholesale price agreement, to maximize the overall profit, the retailer can lower the wholesale price when the risks of the export exchange rate increase, and the supplier can reduce the selling price of raw materials when the risks of import exchange rate rise. 
Furthermore, combining Propositions 3 and 4, under the wholesale price agreement, the wholesale price of products determined by the manufacturer to the retailer has been reduced, while the overall order quantity is increased, which clearly shows the manufacturer's strategic tradeoff between a higherorder quantity and a lower wholesale price.

(iv) Proposition 5 shows that in centralized decisionmaking, when the wholesale price agreements are adopted, as the fluctuations of import and export exchange rate increase, the expected profit of the retailer, the supplier, and the manufacturer will all decrease. Therefore, members in transnational supply chains need to hedge exchange rate risks through forwards, futures, options, currency swaps, and other ways. Particularly, because that the offshore nondeliverable forwards (NDF) market is characterized by rich types of market participants, fewer trading restrictions, and sensitivity to market information, the members should trade more in the offshore NDF foreign exchange market and less in the domestic market. Furthermore, combining Propositions 3-5, when the wholesale price agreements are adopted in the centralized decisionmaking, the wholesale price determined by the manufacturer to the retailer is reduced, the risk hedging ratio of the manufacturer will increase, and the expected profit of the manufacturer will decrease. Therefore, under the risk aggregation, the strategy of "Incentivize the manufacturer to hedge exchange rate risk through lower wholesale price" can achieve the tradeoff between the profit level of the supply chain and risk-taking, and it is a feasible strategy for supply chain risk management.

(v) Proposition 6 suggests that the revenue-sharing contracts can lower the exchange rate risks undertaken by the retailer and the supplier, thus increasing their expected profits. Therefore, when the members in transnational supply chains adopt the revenue-sharing contract, the manufacturer and the retailer can raise the revenue-sharing coefficient to improve their expected profits.

(vi) The simulation results show that centralized decision-making is superior to decentralized decisionmaking for the decision-makers in the transnational supply chain. Thus, in a multinational supply chain of suppliers, retailers, and manufacturers, they can increase the expected profit of centralized decisions through wholesale price agreements or revenuesharing contracts.

\section{Conclusions}

This paper takes the three-echelon transnational supply chain as the research object. Considering the bilateral exchange rate risks of import and export, our study investigates the impact of leading company's financial hedging on the decision-makers of the supply chain. First, we construct the profit functions and decision-making models of each member in the decentralized and centralized supply chains, respectively. In the centralized supply chain, we introduce the incentive mechanism of hedging exchange rate risks with foreign exchange futures. Accordingly, we discuss the influence of financial hedging behavior and the exchange rate risks on the decision-making process of each member from the perspective of wholesale price agreements and revenuesharing contracts, respectively. Second, the relationships of decision variables are explored through simulation analysis, and the results of the decentralized and centralized decisionmaking are compared simultaneously. The main conclusions are as follows:

(i) In decentralized decision-making, under the hedging strategy for exchange rate risks, with the increase of the fluctuations of import and export exchange rates, the manufacturer's expected profit and profit variance will decrease, while the expected profits of the retailer and the supplier will not change.

(ii) In centralized decision-making, when each member adopts the wholesale price agreement, the order quantity and the risk hedging ratio of the manufacturer will increase. Meanwhile, the benchmark wholesale price of the retailer's products decreases with the increase of export exchange rate fluctuations and increases with the rise of the incentive coefficient of risk hedging. The benchmark selling price of the supplier's raw materials increases with the rise of the fluctuation of the import exchange rate and decreases with the increase of the incentive coefficient of risk hedging.

(iii) Different from decentralized decision-making, in centralized decision-making, when each member adopts the revenue-sharing contract, the order quantity of the supply chain is negatively correlated with the fluctuations of import and export exchange rates and the hedging ratio of exchange rate risks.

(iv) Compared with decentralized decision-making, the manufacturer's expected profit declines slightly under the revenue-sharing contract. If the manufacturer adopts a higher ratio of risk hedging, its profit variance will be smaller than that of decentralized decision-making. Furthermore, the expected profits of the retailer and the supplier will significantly increase. Therefore, for the members of the transnational supply chain, centralized decisionmaking is better than decentralized decisionmaking.

There are the following limitations in this paper, which can be solved in future study. First, we excluded the influence of information asymmetry when establishing a three-echelon manufacturer-retailer-supplier supply chain. However, there are many members in the transnational supply chain, and their decision-making behaviors are relatively complex, and the information among them is asymmetrical in practice. This model may be extended 
further, assuming the information asymmetry. Second, this study does not consider the inventory cost, product residual value, and other factors, so future research may combine these factors to investigate exchange rate risk hedging strategy in the transnational supply chain. Third, this paper does not explore the influence of supply and demand risks and financial derivatives with various characteristics on supply chain decision-making. Therefore, future research could generalize our analysis to adopt different portfolios of futures, forwards, and options to study risk hedging strategies of transnational supply chains under the uncertainty of market supply and demand.

\section{Data Availability}

Underlying data supporting the results of our study can be obtained by contacting the corresponding author.

\section{Conflicts of Interest}

The authors declare that they have no conflicts of interest.

\section{Acknowledgments}

This work was supported by the National Natural Science Foundation of China under Grant no. 71171155, Humanities and Social Sciences Research Planning Fund of Ministry of Education under Grant no. 19YJA630080, 2020 Natural Science Basic Research Project of Shaanxi Province under Grant no. 2020JM-447, Xi'an Social Sciences Planning Fund General Projects under Grant no. JX178, National Social Science Foundation of China under Grant no. 20XGL003, and Shaanxi Provincial Social Sciences 2020 Major Theoretical and Realistic Key Research Projects under Grant no. SX-225.

\section{References}

[1] O. Tang and S. Nurmaya Musa, "Identifying risk issues and research advancements in supply chain risk management," International Journal of Production Economics, vol. 133, no. 1, pp. 25-34, 2011.

[2] I. Manuj and J. T. Mentzer, "Global supply chain risk management strategies," International Journal of Physical Distribution \& Logistics Management, vol. 38, no. 3, pp. 192-223, 2008.

[3] Z. Liu and A. Nagurney, "Supply chain outsourcing under exchange rate risk and competition," Omega, vol. 39, no. 5, pp. 539-549, 2011.

[4] T. Ito, S. Koibuchi, K. Sato, and J. Shimizu, "Exchange rate exposure and risk management: the case of Japanese exporting firms," Journal of the Japanese and International Economies, vol. 41, pp. 17-29, 2016.

[5] R. C. Hernán and R. N. Norberto, "Nonlinear state and shock dependence of exchange rate pass through on prices," BIS Working Papers, vol. 32, pp. 17-34, 2018.

[6] S. Mahapatra and S. N. Bhaduri, "Dynamics of the impact of currency fluctuations on stock markets in India: assessing the pricing of exchange rate risks," Borsa Istanbul Review, vol. 19, no. 1, pp. 15-23, 2019.

[7] K.-K. Kim and K. S. Park, "Transferring and sharing exchange-rate risk in a risk-averse supply chain of a multinational firm," European Journal of Operational Research, vol. 237, no. 2, pp. 634-648, 2014.

[8] G. Li, J. Zhu, and J. Li, "Understanding bilateral exchange rate risks," Journal of International Money and Finance, vol. 68, pp. 103-129, 2016.

[9] Q. Huang, J. Weng, S. Ohmori, and K. Yoshimoto, "Profit allocation in the global supply chain with transfer pricing and exchange rate," Procedia Manufacturing, vol. 39, pp. 1715-1723, 2019.

[10] W. Thorbecke, "East Asian value chains, exchange rates, and regional exchange rate arrangements," Journal of Asian Economics, vol. 65, pp. 101-132, 2019.

[11] S. L. Srinivasulu, "Strategic response to foreign exchange risks," The Columbia Journal of World Business, vol. 16, no. 1, pp. 13-23, 1981.

[12] B. Kazaz, "1 $>2$ ? less is more under volatile exchange rates in global supply chains," Business Horizons, vol. 57, no. 4, pp. 521-531, 2014.

[13] B. Chowdhry and J. T. B. Howe, "Corporate risk management for multinational corporations: financial and operational hedging policies," Review of Finance, vol. 2, no. 2, pp. 229-246, 1999.

[14] M. A. Cohen and A. Huchzermeier, "Valuing operational flexibility under exchange rate risk," Operations Research, vol. 44, no. 1, pp. 100-113, 1996.

[15] B. Kazaz, M. Dada, and H. Moskowitz, "Global production planning under exchange-rate uncertainty," Management Science, vol. 51, no. 7, pp. 1101-1119, 2005.

[16] Z. Liu, L. Chen, L. Li, and X. Zhai, "Risk hedging in a supply chain: option vs. price discount," International Journal of Production Economics, vol. 151, pp. 112-120, 2014.

[17] M. Wang and H. Huang, "The design of a flexible capitalconstrained global supply chain by integrating operational and financial strategies," Omega, vol. 88, pp. 40-62, 2019.

[18] E. Bolandifar and Z. Chen, "Hedging through index-based price contracts in commodity-based supply chains," Omega, vol. 90, pp. 97-101, 2020.

[19] R. Caldentey and M. B. Haugh, "Supply contracts with financial hedging," Operations Research, vol. 57, no. 1, pp. 47-65, 2009.

[20] Y.-H. Hung, L. Y. O. Li, and T. C. E. Cheng, "Transfer of newsvendor inventory and supply risks to sub-industry and the public by financial instruments," International Journal of Production Economics, vol. 143, no. 2, pp. 567-573, 2013.

[21] D. Bandaly, L. Shanker, and A. Şatır, "Integrated financial and operational risk management of foreign exchange risk, input commodity price risk and demand uncertainty," IFACPapersOnLine, vol. 51, no. 11, pp. 957-962, 2018.

[22] Z. G. Liu and J. Wang, "Supply chain network equilibrium with strategic financial hedging using futures," European Journal of Operational Research, vol. 272, no. 31, pp. 962-978, 2019.

[23] S. Han, Y. Fu, B. Cao, and Z. Luo, "Pricing and bargaining strategy of e-retail under hybrid operational patterns," Annals of Operations Research, vol. 270, no. 1, pp. 170-200, 2018.

[24] M. Leng, Z. Li, and L. Liang, "Implications for the role of retailers in quality assurance," Production and Operations Management, vol. 25, no. 5, pp. 779-790, 2016.

[25] K. Matsui, "Optimal bargaining timing of a wholesale price for a manufacturer with a retailer in a dual-channel supply chain," European Journal of Operational Research, vol. 287, no. 1, pp. 225-236, 2020.

[26] S. Sinha, N. M. Modak, and S. S. Sana, "An entropic order quantity inventory model for quality assessment considering 
price sensitive demand," Opsearch, vol. 57, no. 1, pp. 88-103, 2020.

[27] R. Udayakumar, K. V. Geetha, and S. S. Sana, "Economic ordering policy for non-instantaneous deteriorating items with price and advertisement dependent demand and permissible delay in payment under inflation," Mathematical Methods in the Applied Sciences, vol. 44, no. 9, pp. 7697-7721, 2021.

[28] Y. Zhang, K. Donohue, and T. H. Cui, "Contract preferences and performance for the loss-averse supplier: buyback vs. Revenue sharing," Management Science, vol. 62, no. 6, pp. 1734-1754, 2016.

[29] B. Hu and Y. Feng, "Optimization and coordination of supply chain with revenue sharing contracts and service requirement under supply and demand uncertainty," International Journal of Production Economics, vol. 183, pp. 185-193, 2017.

[30] C. Y. Liu and Z. L. Yang, "A study on the coordination of revenue-sharing contracts for risk avoidance and promotion under final secondary orders," Operations Research and Management Science, vol. 28, no. 8, pp. 134-140, 2019.

[31] J. Heydari, K. Govindan, and Z. Basiri, "Balancing price and green quality in presence of consumer environmental awareness: a green supply chain coordination approach," International Journal of Production Research, vol. 59, no. 7, pp. 1957-1975, 2020.

[32] Y. B. Li and C. X. Wang, "Supply chain optimization and coordination based on rate of profit to cost," Journal of Technical Economics \& Management, vol. 4, pp. 3-7, 2021.

[33] S. S. Sana, "A structural mathematical model on two echelon supply chain system," Annals of Operations Research, vol. 299, pp. 1-29. In press, 2021. 